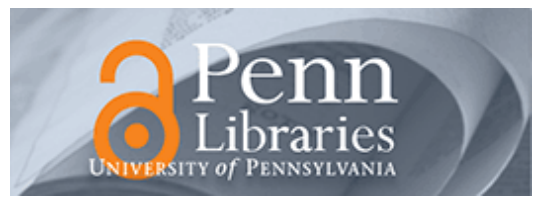

University of Pennsylvania ScholarlyCommons

\title{
Governing Collaborative Activity: Interdependence and the Impact of Coordination and Exploration
}

\author{
Vikas A. Aggarwal \\ Nicolaj Siggelkow \\ University of Pennsylvania \\ Harbir Singh
}

Follow this and additional works at: https://repository.upenn.edu/mgmt_papers

Part of the Business Administration, Management, and Operations Commons

\section{Recommended Citation}

Aggarwal, V. A., Siggelkow, N., \& Singh, H. (2011). Governing Collaborative Activity: Interdependence and the Impact of Coordination and Exploration. Strategic Management Journal, 32 (7), 705-730.

http://dx.doi.org/10.1002/smj.900

This paper is posted at ScholarlyCommons. https://repository.upenn.edu/mgmt_papers/51

For more information, please contact repository@pobox.upenn.edu. 


\title{
Governing Collaborative Activity: Interdependence and the Impact of Coordination and Exploration
}

\author{
Abstract \\ We examine the performance implications of selecting alternate modes of governance in \\ interorganizational alliance relationships. While managers can choose from a range of modes to govern \\ alliances, prior empirical evidence offers limited guidance on the performance impact of this choice. We \\ use an agent-based simulation of interfirm decision making to complement empirical studies in this area. \\ Our results point to a complex interplay between interdependencies, governance structures, and firms' \\ search capabilities. Different patterns of interdependence create varying needs with respect to \\ coordination and exploration, while at the same time different governance modes, coupled with \\ organizational search capabilities, supply varying degrees of these factors. Firm performance in an \\ alliance relationship improves when the needs and supplies of coordination and exploration are matched. \\ We find situations in which stronger organizational search capabilities can backfire, leading to lower \\ exploration within the alliance relationship, and hence to lower firm performance. Moreover, we show that \\ for higher levels of interdependence, coordination can become more critical for firm performance than \\ exploration: unless it is tied to coordination, exploration can be ineffective in alliance settings.
}

\section{Keywords}

alliances, governance modes, coordination, exploration, interdependence, simulation

\section{Disciplines}

Business Administration, Management, and Operations 


\title{
Governing Collaborative Activity: Interdependence and the Impact of Coordination and Exploration
}

By

\author{
Vikas A. Aggarwal* \\ Nicolaj Siggelkow** \\ and
}

Harbir Singh***

Forthcoming in Strategic Management Journal

\section{ACKNOWLEDGEMENTS}

We thank Howard Brenner for programming assistance, and Richard Bettis, Gino Cattani, Sendil Ethiraj, David Hsu, Dan Levinthal, two anonymous reviewers, and conference participants in the Strategic Management Society Conference, the $\Lambda$ tlanta Competitive $\Lambda$ dvantage Conference and the $\Lambda$ cademy of Management meetings, for thoughtful comments. We gratefully acknowledge the Mack Center for Technological Innovation at the Wharton School and the INSEAD-Wharton Center for Global Research and Education for generous funding.

* $\quad$ Assistant Professor of Entrepreneurship and Family Enterprise at INSE $\Lambda$ D, Boulevard de Constance, 77300 Fontainebleau, France

Email: vikas.aggarwal $(a)$ insead.edu

** Professor of Management at The Wharton School, University of Pennsylvania, 2000 Steinberg Hall

Dietrich Hall, Philadelphia, PA 19104-6370, USA

Email: siggelkow $(a)$ wharton.upenn.edu

*** Professor of Management at The Wharton School, University of Pennsylvania, 2000 Steinberg Hall Dietrich Hall, Philadelphia, PA 19104-6370, USA

Email: singhh $(a$, wharton.upenn.edu

$\Lambda$ working paper in the INSEAD Working Paper Series is intended as a means whereby a faculty researcher's thoughts and findings may be communicated to interested readers. The paper should be considered preliminary in nature and may require revision.

Printed at INSE $\Lambda$ D, Fontainebleau, France. Kindly do not reproduce or circulate without permission. 


\begin{abstract}
We examine the performance implications of selecting alternate modes of governance in interorganizational alliance relationships. While managers can choose from a range of modes to govern alliances, prior empirical evidence offers limited guidance on the performance impact of this choice. We use an agent-based simulation of inter-firm decision making to complement empirical studies in this area. Our results point to a complex interplay between interdependencies, governance structures and firms' search capabilities: different patterns of interdependence create varying needs with respect to coordination and exploration, while at the same time different governance modes, coupled with organizational search capabilities, supply varying degrees of these factors; firm performance in an alliance relationship improves when the needs and supplies of coordination and exploration are matched. We find situations in which stronger organizational search capabilities can backfire, leading to lower exploration within the alliance relationship, and hence to lower firm performance. Moreover we show that for higher levels of interdependence, coordination can become more critical for firm performance than exploration: unless it is tied to coordination, exploration can be ineffective in alliance settings.
\end{abstract}

Running Head: Governing Collaborative Activity

Keywords: Alliances; governance modes; coordination; exploration; interdependence; simulation 


\section{INTRODUCTION}

Inter-firm collaborative relationships are a growing phenomenon with significant organizational and performance consequences (Reuer, 2004). Engaging in such relationships requires determining how to govern the shared activities - a particularly important consideration when the activities associated with the collaboration interact with the other activities of the participating firms. Broader firm-level consequences can often result from governance mode selection. In resource-constrained environments, for example, firms may be unable to invest in the capabilities necessary to pursue different modes of governance across multiple alliance relationships. As a result, developing a business model around a single, particular mode can become a necessary strategic choice.

While governance mode choice can have strategic implications, there is limited direct evidence for the impact of different modes on firm performance. Prior work in this area has generally addressed two issues: first, does cooperative activity matter? And second, what factors compel firms to select alternate modes of governance in cooperative settings? Empirical evidence for the implications of cooperative activity has been mixed: while some work documents the positive effects of such activity on firm performance using metrics such as stock market returns (Das, Sen and Sengupta, 1998) and patenting output (Shan, Walker and Kogut, 1994), other studies suggest that cooperative activity plays a more limited role in influencing firm-level outcomes relative to factors such as internal capabilities (Lee, Lee and Pennings, 2001). More robust evidence exists with respect to the antecedents of such activity. Two streams of prior work have addressed the determinants of alliance governance: a transaction cost economics (TCE) view, which generally concludes that more hierarchical forms of governance are associated with transactions characterized by increased appropriation hazards (e.g., Pisano, 1989; Oxley, 1997); and an organizational approach, which examines the choice between alternate modes of governance taking into account firm-level considerations (e.g., Gulati and Singh, 1998; Kale and Puranam, 2004; Dyer et al., 2004; Villalonga and McGahan, 2005; Aggarwal and Hsu, 2009).

Although ample work has assessed alliance governance mode determinants, less is known about the performance implications of difference modes. Sampson (2004) makes important headway towards addressing this by focusing on the implications of 'governance misalignment'. Using TCE as a theoretical prior, this study focuses on the innovation implications of governance choices that run counter to TCE predictions. The empirical finding that misaligned choices can 
have adverse innovation effects is compelling, as it motivates the notion that mode choice has performance effects determined in part by the nature of inter-firm characteristics. Moreover, it suggests the need for a deeper understanding of the mechanisms influencing firm performance as governance modes vary.

Our central research question addresses this link between governance mode and performance: how does the governance mode used to manage decisions in the context of an interorganizational relationship between two firms impact firm performance? To examine this question, we employ an agent-based simulation that enables us to develop a more nuanced view of the implications of governance choice. Part of the motivation underlying this approach is to better understand some of the factors underlying the implications of cooperative activity that may be more difficult to address using empirical approaches. Prior studies exploring firm performance in alliance settings, for example, have explored moderating effects such as alliance activity type (e.g., marketing vs. technical) and relative firm size, while abstracting away from the particular implications of firm characteristics and governance mode. Omitting such characteristics may be the reason for the mixed results around the implications of cooperative activity noted above. By utilizing a simulation methodology, we are afforded a degree of flexibility in experimental design not possible with alternative approaches.

We use a simulation model with the aim of generating a novel set of insights (following from a set of assumptions) that can guide future theoretical and empirical work. To develop our model we draw from a rich body of literature that has used agent-based simulations to address issues of organizational strategy (e.g., Levinthal, 1997) and from prior work examining interorganizational relationships. We model a range of governance structures, different patterns of interdependencies, and varying levels of organizational capabilities. To anchor our analytical explorations, we first outline a conceptual framework of firm performance, building on the information processing and contingency theories of the firm. With this framework in mind, we then use the simulation to generate further insight into the mechanisms underlying the performance effects of alternate governance modes. In the final section, we discuss theoretical implications and outline several specific insights and hypotheses that emerge from this study. ${ }^{1}$

\footnotetext{
I Many of the theoretical mechanisıns we discuss might also be relevant in intra-firm settings, and our theoretical development and discussion moreover draw on a broad range of the organizational design literature examining within-firm issues. Since our focus is on alliance governance, however, we construct a simulation
} 


\section{THEORY AND LITERATURE}

Our aim in this section is to develop a conceptual framework that describes a number of mechanisms underlying firm performance in alliance settings. We begin by discussing governance mode choice and inter-firm interdependence; we then turn to the factors of coordination and exploration. We motivate our framework with a discussion of prior literature, including work on organization design and information processing. The framework, in turn, motivates the simulation model discussed in the subsequent section.

\section{Governance modes and interdependence}

An important question in any inter-organizational relationship is how to govern the shared activities. An early stream of work examining the governance choice issue drew from transaction cost theory (Williamson, 1975; Klein, Crawford and Alchian, 1978). In this context, appropriation concerns arising from contractual hazards become a central consideration. Gulati and Singh (1998) pick up on this thread, discussing appropriation concerns as an important determinant of governance structure, while at the same time suggesting that coordination costs play an equally important role. They draw from the organization design literature (e.g., Thompson, 1967; Galbraith, 1977) to suggest that interdependence is a particularly important factor in determining how firms structure alliance relationships. Interdependence in an alliance setting can encompass factors such as sharing complementary technologies and production facilities, as well as joint product development (these are among the activities Gulati and Singh discuss in measuring interdependence).

The importance of interdependence both among activities in which firms are jointly engaged and between the firms' alliance and non-alliance activities stems from the information processing needs of the interacting firms. In his discussion of intra-organizational design, Galbraith (1977: 37) notes that "in order to coordinate interdependent roles, organizations have invented mechanisms for collecting information, deciding, and disseminating information to resolve conflicts and guide interdependent actions." Information plays a similar role in alliance 
settings: just as greater levels of internal interdependence lead to higher task uncertainty and increased information processing needs within an organization (Tushman and Nadler, 1978), greater levels of interdependence within and between the activities of firms in an alliance lead to higher alliance-related information processing needs. As a result, alliance design choices are driven by the need to capture and effectively manage interdependence-related information.

Bounded rationality (Simon, 1945; Cyert and March, 1963) in many ways underpins the information processing perspective: if actors were unboundedly rational, a single decision maker could simply optimize across all combinatorial possibilities; yet with limits on individual information processing ability, a more decentralized approach will likely prevail (Mintzberg 1979). In the context of alliance relationships, therefore, firms are likely to (at least partially) decentralize decision making in order to deal with information flows arising from inter-firm interdependence. As prior work examining within-firm organizational structures has demonstrated, information flows are a core consideration in optimally configuring organizations, particularly with varying levels of decomposability (Burton and Obel, 1980; Simon, 1996). More generally, just as environmental contingencies drive different choices of within-firm organization (e.g. Lawrence and Lorsch, 1967) we would expect that no single alliance governance choice would apply equally effectively across all circumstances. Varying information processing requirements associated with different patterns of interdependence between firms will likely necessitate employing alternative structures to govern the associated decisions. This discussion therefore suggests:

- Proposition 1. The pattern of activity interdependence between firms in an alliance creates performance differences among different alliance governance modes.

\section{Coordination, exploration and firm performance}

To understand how interdependence can influence the link between governance choice and performance, we seek to better understand the levers that firms employ to influence performance in alliance settings. Coordination is one such lever: the nature and functioning of coordination mechanisms and the associated failures to appropriately coordinate activities have been a central set of concerns for both the classic and the more recent organization design literature (e.g., Simon, 1945; Galbraith, 1977, Burton and Obel, 1984; Rivkin and Siggelkow, 2003). While 
many of these studies have focused on intra-firm interactions, work going back to (at least) Schelling (1960) has discussed issues of coordination across multiple organizations. In the particular context of alliance relationships, Gulati and Singh (1998) suggest that firms take into account coordination concerns in making governance mode decisions. Moreover, a recent stream of alliance research looking at firm adaptation and the development of routines over time suggests that the ability to effectively coordinate activities among firms can be an important driver of firm performance (e.g., Zollo et al. (2002), Gulati, Lawrence and Puranam (2005)).

In addition to the ability to coordinate among activities, a firm's ability to explore and find new activities can be an important driver of performance in an alliance. Exploration is a core element of the behavioral theory of the firm (Cyert and March, 1963), with search processes critical to a firm's ability to adapt and evolve (Nelson and Winter, 1982; March, 1991; Levinthal, 1997). As March (1991) suggests, exploration, a concept captured by ideas such as "search, variation, risk taking, experimentation, play, flexibility, discovery, innovation," is critical for organizations. Moreover, search can be exploratory to varying degrees, from narrow, local search to broader search. The drivers of exploration have been addressed in a growing body of work, with factors such as organizational structure shown to play an important role (e.g., Siggelkow and Rivkin, 2005, 2006 and references therein). We build on this work in the present study, while at the same time shifting the focus to exploration in an inter-organizational setting. ${ }^{2}$

The prior literature suggests, therefore, that coordination and exploration have important effects on firm performance. Moreover, the degree of coordination and exploration that will be required in an alliance setting is, in turn, likely to be influenced by the pattern of inter-firm interdependence: greater interdependence increases the challenges of coordination (e.g., Galbraith, 1977) and requires a higher degree of exploration because interdependencies create more rugged performance landscapes that can cause firms to get stuck with very suboptimal choices (e.g., Levinthal, 1997). This discussion therefore suggests:

\footnotetext{
2 Our definition of "exploration" refers to organizational actions related to finding new activity configurations. Our use of the term exploration is thus consistent with what is more generally termed "search" in prior literature (see, e.g., Siggelkow and Rivkin's (2006) discussion of exploration). March's (1991) further distinction between exploitation and exploration is embedded implicitly in our model (see below), as we vary the breadth of search undertaken by managers from narrow (akin to "exploitation") to broad (akin to "exploration" in March's (1991) more particular sense).
} 
- Proposition 2a. Different patterns of activity interdependence between firms create different needs for coordination and exploration in an alliance relationship.

While interdependence patterns create varying needs for coordination and exploration, the supply of these factors is influenced both by the alliance governance structure and by organizational capabilities. More specifically, in alliance relationships, a primary consideration is the degree of autonomy held by the individual firms. Two core considerations in such a setting are (1) the information flows enabling individual actors to make decisions, and (2) the overarching processes governing these decisions. We refer to the collective set of factors that characterize the underlying information flow and decision processes as the alliance governance structure, and suggest that the particular structure employed influences the supply of coordination and exploration in inter-organizational relationships. We discuss these structures in more detail in the following section.

Beyond the particular governance structure employed, internal firm capabilities are also likely to play an important role. A broad stream of the organizational strategy literature has focused on the role of capabilities in the formation, governance and performance of collaborative relationships (e.g., Kale, Dyer and Singh, 2002; Zollo et al., 2002; Colombo, 2003; Leiblein and Miller, 2003; Mayer and Salomon, 2006). In this paper, we conceptualize capabilities as a set of factors that enable an organization to engage, to varying degrees, in the search for better configurations of performance-relevant activities. We use the term "organizational search capabilities" to denote these factors in our conceptual framework and simulation model. ${ }^{3}$ Such capabilities represent the end product of investments by firms in their ability to generate new ideas and evaluate alternative courses of action. As a result, these capabilities may be static in the context of an individual alliance relationship, but adjustable over time as firms alter their investments in decision evaluation resources. This discussion thus suggests that as firms seek to respond to the coordination and exploration needs arising from inter-firm interdependence they will draw on the joint effects of governance modes and organizational search capabilities. As a result, we have:

\footnotetext{
${ }^{3}$ We defer a more detailed discussion of these capabilities to the Simulation Model section, where we describe the particular types of such capabilities we model in this paper.
} 
- Proposition 2b. Different governance structures and organizational search capabilities supply different degrees of coordination and exploration in an alliance relationship.

Finally, as much of the organizations literature (e.g., Lawrence and Lorsch, 1967; Galbraith, 1977; Burton and Obel, 1995; Volberda, 1996) collectively indicates, higher performance stems from situations in which firms are adequately equipped to deal with the demands arising from their particular form of interdependence. As our discussion has suggested, in the case of alliance relationships, coordination and exploration are core considerations. Moreover, as Tushman and Nadler (1978: 619) note, "too much capacity will be redundant and costly; too little capacity will not get the job done". Thus, firms in an alliance will be more likely to achieve higher performance when they are able to strike a balance between the needs and supply of coordination and exploration. This discussion thus suggests:

- Proposition 3. Firm performance in an alliance relationship improves when coordination and exploration needs are matched with the degree of coordination and exploration supplied.

The conceptual framework illustrated in Figure 1 summarizes our discussion thus far: The demands for coordination and exploration are inherently influenced by the pattern of interdependence among the activities in which the firms involved in the inter-organizational relationship are engaged. As interdependence increases, so too will the need to coordinate actions among firms; similarly, a higher degree of interdependence will create greater landscape complexity, necessitating higher levels of exploration (e.g., Levinthal, 1997). While interdependence has implications for coordination and exploration demands, governance mode and organizational search capabilities have supply implications for these factors: mode choice affects the nature and extent of coordination among firms, as well as the ability of firms to explore their environment. Likewise, organizational search capabilities affect the supply of exploration and, in the interplay with the chosen governance mode, coordination. We turn in the next section to describing a simulation model that enables us to explore this framework in greater detail.

Insert Figure 1 about here 


\section{SIMULATION MODEL}

To develop our simulation model, we build on and extend prior work that has used the $N K$ framework (Kauffman, 1993) to model firm decision making (e.g., Levinthal, 1997; Lenox, Rockart and Lewin, 2006). This literature generally envisions firms as sets of interdependent choices, an approach characteristic of an activity systems view of organizations (Porter, 1996; Siggelkow, 2001, 2002). In particular, a firm is seen as having to resolve a set of $N$ 'policy choices.' For instance, a firm may have to decide whether to increase its product variety, whether to engage in various marketing campaigns, or whether to increase its budget for sales force training. The $N K$ model further assumes that the benefit that is derived from each policy choice is affected by $K$ other policy choices. For instance, the value that an increase in product variety may generate could depend on whether the sales force has been recently trained, or not. In sum, each unique configuration of the $N$ choices generates a particular performance value. Thus, we can imagine a performance landscape on $N+1$ dimensions: $N$ 'horizontal' dimensions representing the space of all possible alternatives for each of the $N$ policy choices, and one 'vertical' dimension representing the performance level resulting from each overall choice configuration (of the $N$ decisions). Landscape complexity depends on interactions among the policy choices, and firms search the landscape attempting to move to higher performance levels by altering individual choices.

The two principal components of $N K$ models are thus (1) a mechanism to create performance landscapes (i.e., the mapping from choices to performance), and (2) a set of decision rules that describe how firms search the landscape (i.e., how firms generate and assess alternative choice configurations). In describing our model, we focus first on extending the concepts of interdependence and performance landscapes to a two-firm setting. We then discuss our model of search and governance in this context.

\section{Patterns of interdependence}

We model two firms interacting within the context of an alliance relationship. Firms 1 and 2 are each composed of a set of binary policy choices which we denote as $F_{1}$ and $F_{2}$. We decompose the policy choice sets of each firm into two groups: (1) non-alliances choices under the control of the respective firm and (2) choices that are part of the alliance relationship. For Firm 1, we thus have $F_{l}=\left\{N_{l}, A_{l}\right\}$, where $N_{l}$ represents the set of non-alliance choices, and $A_{l}$ represents the set 
of alliance-dedicated activities in which Firm 1 is engaged. For example, an R\&D alliance between two technology firms might consist of joint work towards a particular product. Choices with respect to this R\&D alliance that Firm 1 has to resolve, e.g., whether or not to dedicate a particular engineer to this alliance, would be included in $A_{l}$. Other choices that do not fall into the province of the alliance such as how much to invest in branding an existing product would be included in $N_{l}$. We denote the number of policy choices in sets $N_{l}$ and $A_{l}$ with $n_{l}$ and $a_{l}$, and define analogous values for Firm 2. The total number of policy choices in the system of two firms is thus $N \equiv n_{1}+a_{1}+a_{2}+n_{2}$.

Having defined the policy choices for each firm, we can define the pattern of interactions among them. Figure 2a illustrates an interaction matrix for two firms with $n_{l}=4, a_{l}=2, a_{2}=2$, and $n_{2}=4$. The matrix specifies which policy choices are affected by which other choices. An $X$ in row $i$, column $j$, signifies that the resolution of the $j^{\text {th }}$ policy choice affects the value of the $i^{\text {th }}$ policy choice. Using this matrix, we can specify exactly which policy choices affect which other policy choices. For instance, in the example given in Figure $2 \mathrm{a}, d_{l}$ is affected by $d_{l}$ through $d_{8}$. Likewise, $d_{9}$ is affected by $d_{5}$ through $d_{l-}$. For ease of notation, we denote individual policy decisions by $d_{i}$, where $i$ is indexed from 1 to $N$, and sequentially number the decisions in the sets $N_{l}, A_{l}, A_{2}$, and $N_{2}$. Thus for Figure $2 \mathrm{a}$, we have $N_{1}=\left(d_{1}, d_{2}, d_{3}, d_{4}\right), A_{1}=\left(d_{5}, d_{6}\right), A_{2}=\left(d_{7}, d_{8}\right)$, and $N_{2}=\left(d_{9}, d_{10}, d_{11}, d_{12}\right)$. We further define the full vector of decisions in the entire system of the two firms as $d \equiv\left(d_{l}\right.$, $\left.d_{2}, \ldots, d_{N}\right)$. Since decisions are binary, $\boldsymbol{d}$ is thus a string of $N 0$ 's and 1 's.

To analyze the role played by different patterns of interdependence on optimal governance mode choice, we construct a set of specific interdependence patterns. These patterns follow a logical sequence, increasing in overall complexity, with the differences between any two consecutive patterns arising from the addition of a particular type of interdependence. Figure $2 b$ shows the patterns we use, with shaded areas representing the presence of interactions. (Each shaded "box" in Figure $2 b$ is completely filled with X's.) We model a system of 12 policy choices with $n_{I}=4, a_{I}=2, a_{2}=2$ and $n_{2}=4$. Pattern 1 is "fully decomposable," i.e., it has interactions occurring solely within each group of policy choices. For instance, choices in $N_{l}$ only affect other choices in $N_{l}$; similarly for choices in $A_{l}, A_{2}$, and $N_{2}$. Pattern 2, "pure alliance interaction," introduces interactions among the alliance choices of the two firms, i.e., between $A_{l}$ and $A_{2}$. Thus, in this pattern all the activities within the alliance affect each other, but none of the alliance activities interact with any of the non-alliance activities. Pattern 3, "firm-alliance interaction," 
introduces interactions among all the alliance and non-alliance choices within each firm. Thus, in this case, choices within $A_{I}$ and $A_{2}$ interact with choices within $N_{I}$ and $N_{2}$. All activities within the alliance continue to interact with each other. (The pattern depicted in Figure 2a corresponds to Pattern 3.) Lastly, in Pattern 4, "full interdependence," all activities, even the non-alliance activities of the two firms interact with each other. ${ }^{4}$

Insert Figure 2 about here

\section{Performance landscapes}

We turn next to the mechanism for assessing performance in our model. Prior literature (e.g., Levinthal, 1997; Rivkin and Siggelkow, 2003) has used the 'contributions' of individual policy choices to describe performance in an $N K$ setting. We follow a similar approach. For each policy choice $d_{i}$ in our system, we construct a contribution value function, $C_{i}$. The contribution value function takes as arguments each of the $k_{i}+1$ choices affecting $d_{i}$ (this includes $d_{i}$ itself, as well as the other $k_{i}$ choices affecting $d_{i}$ as defined by the interaction matrix). Each contribution value function $C_{i}$ is constructed as follows: for each unique configuration of policy choice $d_{i}$ and the $k_{i}$ other choices affecting it, we draw a random 'contribution value' from the uniform distribution $[0,1] .^{5}$ Once all possible contribution values for each individual choice are defined, the performance for any particular set of policy choices is computed as the sum of the contribution values associated with these choices.

To reduce statistical artifacts that could arise from the stochastic nature of the landscape generation process, we normalize performance by the highest value possible on any given landscape. Let $d^{*}$ be the policy choice configuration that leads to the highest performance $\Pi^{*}$, i.c., $\Pi^{*}=\sum_{i=1}^{12} C_{i}\left(d^{*}\right)$. Then, for instance, if the performance of Firm 1 is determined only by the contributions of the first six policy choices, the performance of Firm 1 for any choice configuration $\boldsymbol{d}$ is given by $\sum_{i=1}^{6} C_{i}(\boldsymbol{d}) / \Pi^{*}$. In the case of an alliance between Firm 1 and Firm 2

\footnotetext{
${ }^{4}$ While this set of patterns is not exhaustive of the full set of possible interdependencies, they are sufficient for our purpose in that they enable us to create varying types of coordination needs that we can then systematically examine.

${ }^{5} \Lambda \mathrm{s}$ an example, if the interaction matrix has $8 \mathrm{X}$ 's in row $i$ (including the $\mathrm{X}$ in column $i$ ), then the contribution value function $C_{i}$ can take on $2^{8}=256$ possible values for $C_{i}$ depending on how the vector $\boldsymbol{d}$ is configured (i.e., $C_{i}(d)$ will depend only on the values of the 8 choices noted by X's in the interaction matrix).
} 
involving policies 4 through 8 , Firm 1's performance would be determined by the contributions of both Firm 1's non-alliance policy choices $\left(d_{l}\right.$ through $\left.d_{4}\right)$ and by the policy choices of the alliance ( $d_{5}$ through $d_{s}$ ). For instance, if Firm 1 obtains portion $\alpha$ of the alliance performance, Firm 1's overall performance would be computed as $\left(\sum_{i=1}^{4} C_{i}(\mathrm{~d})+\alpha \sum_{i=5}^{8} C_{i}(\mathrm{~d})\right) / \Pi^{*}$.

\section{Agents and search capabilities}

We turn now to the set of decision making rules that govern agents' behavior in our simulation. We define an agent as a decision maker having authority over some subset of policy choices in the two-firm system. For instance, a particular agent might have authority (and care about the performance of) all of the non-alliance activities of Firm 1. One should note that we use the term "agent" for expositional simplicity. An "agent" in our model need not be (and in practice rarely would be) a single person. An agent in our model is the relevant "decision-making-body" that is responsible for making decisions concerning a set of activities, and thus could be a steering committee, a set of managers, etc.

For a given simulation run, we begin by placing the agents at a random point on the landscape (i.e., assigning random starting values to their policy choices). In each subsequent period, the agents make decisions whether to alter the policy choices under their control (i.e., to change a policy from a 0 to 1 , or vice versa). This is done by evaluating a set of possibilities, which is influenced by the organizational search capabilities, and selecting the best option from this set. The determination of what constitutes a 'best option' is, as we will describe below, dependent on the particular governance structure. Before discussing the governance structures in more detail, we describe our conceptualization of organizational search capabilities, which we model as the ability of agents to generate and evaluate alternative configurations for the set of policy choices they control. This set of parameters can be thought of as the degree to which organizational decision-making units are endowed with resources necessary to make decisions in an alliance context.

We model two dimensions of such capabilities: (1) the ability to make simultaneous decisions over a larger vs. smaller number of the policy choices controlled, which we term the 'search radius' as per prior literature (e.g., Siggelkow and Rivkin, 2005), and (2) the ability to evaluate a larger vs. smaller number of alternatives in a given period. 
For the search radius (parameter SR), we model a base case in which agents can change only a single policy choice in each period $(\mathrm{SR}=1)$, as well as a more complex case in which agents can change up to two policy choices simultaneously in each period $(\mathrm{SR}=2)$. For the number of alternatives (parameter ALT), we model a case where agents only evaluate a single, randomly chosen alternative in each period $(\mathrm{ALT}=1)$, as well as a more complex case where all alternatives that lie within the search radius are evaluated $($ ALT $=\max )$. For example, assume an agent controls three policies that are currently configured as 000 . If the agent's search radius is 1 , and she evaluates all alternatives, she considers 100,010 , and 001 . If she evaluates only a single alternative, she will randomly pick one of these, e.g., 010 . If her search radius is 2 , she can also consider options that are different from the current configuration in two policies such as 110 . In this case, were she to evaluate all alternative in her search radius, she would evaluate ${ }_{2}^{3} \mathrm{C}+{ }_{1}^{3} \mathrm{C}$ $=6$ alternatives. In sum, we model four different levels of organizational capabilities. Level A: $\mathrm{SR}=1 \& \mathrm{ALT}=1 ;$ Level B: $\mathrm{SR}=1 \& \mathrm{ALT}=\max ;$ Level $\mathrm{C}: \mathrm{SR}=2 \& \mathrm{ALT}=1 ;$ Level $\mathrm{D}: \mathrm{SR}=$ $2 \& \mathrm{ALT}=\max$.

\section{Governance modes}

We turn next to the different governance modes, which determine the specifics of the decision making process. We construct these modes along four dimensions: (1) number of decision makers (agents), (2) order of decision making, (3) metrics used to evaluate the implications of choices, and (4) nature of oversight and hierarchy around the decision making process. These dimensions represent key elements of organization and alliance design (Simon, 1945; Galbraith, 1977; Reuer, 2004), enabling us to create a range of governance modes that differ in the underlying information flow within and across organizations. We discuss the motivation underlying each dimension and the resulting governance modes in the remainder of this section.

The number of decision makers in the system is an important dimension of variance in structuring alliance governance. Since we are modeling a two-firm system, having two separate decision makers, one for each firm, is a natural baseline. Alternatively, a more integrated level of governance might entail having a single decision maker, while a situation in which there are two decision makers for the firms, along with a third decision maker for the alliance function, would be a natural characteristic of hybrid governance forms. A three-agent model might thus have a decision-making body specific to alliance policy choices (e.g., a joint committee from both firms 
managing the alliance activities). As a second dimension of variance we consider the question of how decision making is ordered, i.e., who gets priority in the decision making process. Decision making order has implications for information flow within organizations, and as discussed in depth in the previous section, such issues are likely to be central to the governance of interorganizational relationships.

The third dimension of variance relates to the metrics used by individual agents to make decisions. Such decision metrics can be thought of as the incentives for individual organizational units, which derive from the particular contractual features of the alliance (e.g., Robinson and Stuart, 2007). We model decision metrics (which are defined solely by the governance mode) as the set of contribution values an agent takes into account in making choices. As an example, in one particular governance mode an agent will consider just the contribution values of the decisions over which she has control. In an alternate governance mode, the agent will consider not only the contribution values of her own decisions, but also some portion of the contribution values of other agents' decisions. ${ }^{6}$

Finally, the fourth dimension of variance we consider is the nature of hierarchy among agents in the model. Alliances can incorporate elements of hierarchical governance (e.g., Hennart 1993) such that decisions taken by one agent need to be ratified by another before they can be implemented. Such hierarchy can, like the decision metrics, derive from the particular contractual arrangements of the alliance. It is different, however, in that it describes the overall organization of decision-making within the organization, rather than the more narrowly-prescribed underlying incentives for individual agents.

Having described the four dimensions along which we model the governance of a particular relationship, we now describe the governance structures we use in our analysis (Figure 3). We model four structures, which we term 'modular', 'self-governing alliance', 'ratified alliance', and 'integrated'. The modular and integrated forms lie at opposite ends of the governance spectrum. With the modular form, there are two agents, each controlling the policy

\footnotetext{
${ }^{6}$ Defining agents' decision metrics in this way implies that we abstract away from a direct analysis of factors such as shirking that may result from, for example, under-enforcement of contracts. Although agents do act opportunistically in that their profit calculations consider only their own pre-defined set of contribution values to the possible detriment of the other agents and the system as a whole, we do not directly model situations where issues of trust are at play, or where agents directly seek to mislead. This is consistent with the notion of selfinterest in, for example Klein, Crawford and Alchian (1978), but may not include the 'guile' component of Williamson's (1975) definition of opportunism, where there are hazards associated with the contract itself.
} 
choices of either Firm 1 or Firm 2 (thus, in our model, six policy choices for each agent). These agents make choices simultaneously, and only consider the profits for their own firm in making decisions, $\sum_{i=1}^{6} C_{i}(d) / \Pi^{*}$ and $\sum_{i=7}^{12} C_{i}(d) / \Pi^{*}$, respectively. This is a simple case of an armslength inter-organizational relationship with no formal decision making structure to govern joint activities. At the other end of the spectrum, we have the integrated mode, where a single agent manages choices for both Firms 1 and 2 (thus, 12 total policy choices in our model). In this case, the agent takes into account the total combined profit of Firms 1 and $2, \sum_{i=1}^{12} C_{i}(d) / \Pi^{*}$, and the individual firms thus operate as a quasi-integrated entity.

In addition, we model two hybrid alliance forms, both of which have an alliance manager who manages the alliance choices (the four choices in the sets $A_{l}$ and $A_{2}$ in our model), while agents for Firms 1 and 2 manage the non-alliance choices of the two firms $\left(N_{1}\right.$ and $N_{2}$ respectively). In both cases, the alliance function takes into account only its own profits $\sum_{i=5}^{8} C_{i}(d) / \Pi^{*}$ when making decisions. Each individual firm, in turn, takes into account the profits associated with its own choices, along with a portion $(\alpha)$ of the alliance profit (we set $\alpha$ to $1 / 2$ in our analysis), i.e., $\left(\sum_{i=1}^{4} C_{i}(\mathrm{~d})+\frac{1}{2} \sum_{i=5}^{8} C_{i}(\mathrm{~d})\right) / \Pi^{*}$ for Firm 1 and $\left(\sum_{i=9}^{12} C_{i}(\mathrm{~d})+\frac{1}{2} \sum_{i=5}^{8} C_{i}(\mathrm{~d})\right) / \Pi *$ for Firm 2. The main difference between the two alliance modes lies in the degree of importance placed on the agendas of the individual firms relative to the agenda of the alliance. In the self-governing alliance mode, the alliance agent is allowed to move first, and the agents for Firms 1 and 2 move second, knowing the alliance's move in the current period. Thus, in this governance mode, the agenda of the alliance is given a high priority.

By contrast, in the ratified alliance mode, the agents for Firms 1 and 2 move first, followed by the alliance agent, who knows the choices made by the two firms in the current period. The alliance agent, however, cannot directly implement changes in policy choices. Rather, the agent ranks the available alternatives and sends this ranked set to the two firm agents, who must 'ratify' the alliance agent's proposals. Ratification requires that both firm agents accept an alliance proposal; a firm agent accepts a proposal if the proposal does not reduce profit for the agent (conditional on the move the agent already made at the start of the period). In this case, the 
agendas of Firms 1 and 2 come first, and are accounted for as the alliance proposals are considered.

Insert Figure 3 about here

\section{RESULTS AND ANALYSIS}

We begin this section by explaining our analytic approach and presenting a number of initial results. We then focus on interdependence, governance structure and capabilities in more detail, outlining how these factors impact the demand and supply of coordination and exploration. In this context, we develop a set of metrics for coordination and exploration that allow us to more precisely show the underlying mechanisms at work. With these metrics, we then discuss the mechanisms underlying the relationship between appropriate governance choice and patterns of interdependence.

\section{Analytic approach and motivating results}

We conducted a broad range of simulations aimed at understanding the implications of joint variation in interdependence, exploration ability and governance mode. As noted previously, we model a 12-policy choice system of 2 firms in which $n_{l}=4, a_{l}=2, a_{2}=2$, and $n_{2}=4$. Since the system itself, along with the factors we model (like the patterns of interdependence), is symmetric for both firms, the performance results for the two firms in the system are equal when run over a large number of landscapes. To facilitate comparison with the integrated structure (which is comprised of all 12 policy choices), we report values for the full system. Performances of individual firms are simply $1 / 2$ of the values reported for the entire system.

Each 'period' in the simulation consists of the agents making a set of decisions with respect to their activities as per the governance mode under which they are operating (see Figure 3). ${ }^{7}$ We run the simulation for 200 periods on a given landscape in order to observe the long-run performance of the firms in the system. To ensure that our results are not driven by statistical

\footnotetext{
${ }^{7}$ For example, with the Ratified $\Lambda$ lliance mode, the following happens within a single period: the agents for Firms 1 and 2 simultaneously make a decision with respect to their activity sets $\mathrm{N}_{1}$ and $\mathrm{N}_{2}$; the alliance then evaluates alternatives for their activity set $\Lambda_{1}-\Lambda_{2}$ (taking into account the new choices within $N_{1}$ and $N_{2}$ ) and sends a ranked set of the alternatives to the agents for Firms 1 and 2 . Finally, the Firm 1 and 2 agents decide whether to ratify the choice made by the alliance.
} 
artifacts, we repeat each simulation 10,000 times. Thus any reported performance value for a particular time period (e.g., period 200) on a particular pattern of interdependence is an average over 10,000 simulation runs (i.e., landscapes). In general, except where explicitly noted otherwise, reported performance differences are statistically significant at the $1 \%$ (or lower) confidence level.

We begin the analysis by examining the performance outcomes of the various governance forms under Pattern 1, the fully decomposable pattern. Figure 4 illustrates the performance of the four governance modes on this interdependence pattern for the four different levels of organizational capability. For capability level A (narrow search radius and one alternative evaluated in each period), in the short run, the integrated mode has the lowest level of performance, while the alliance modes perform best. (For this pattern, the two alliance modes generate the same performance; hence their lines are indistinguishable in the Figure.) In the long run, however, each of the governance modes converges to the same level of performance. A broadening of the search radius (moving from capability level A to level C) preserves the relative short-run differences between governance modes, while enabling each of the modes to arrive at a higher long-run level of performance. An increase in the number of alternatives (moving from level A to level B, or from $\mathrm{C}$ to $\mathrm{D}$ ) increases the speed with which the governance forms converge to the long-run maximum, yet does not affect the level of the long-run performance.

The Pattern 1 results are directly linked to its decomposable nature, i.e., to the fact that there are no interdependencies either between the individual firms and the alliance, or between the firms themselves. As a result, performance speed is driven by the number of agents in the system, since each agent is able to act in parallel and independent of the others. The integrated structure, which relies on one central agent to make all decisions, thus has the lowest short-run performance, while the two alliance forms, each of which has three agents who can work in parallel, have the highest short-run performance. The modular form, with two agents, falls in the middle. In the long run, however, given that the system can be fully decomposed, each mode eventually arrives at the same performance level. Changes in organizational capability operate as expected: an increase in the number of alternatives increases the speed with which each mode 
increases its performance, while an increased search radius enables all firms to reach higher performance levels over time. ${ }^{8}$

Insert Figure 4 about here

Turning next to Figure 5, we examine the performance of the different governance modes on Pattern 4, the fully interdependent pattern, applying the same varying levels of organizational capabilities as before. Here, the results are much more complex. Turning first to the case of capability level A, we see that in contrast to the Pattern 1 case, performance across the four governance modes differs in the long run. In addition, modes vary in their relative performance over time. The integrated mode initially outperforms the other three modes; in the long run, however, it is the lowest performing mode. The modular form, by contrast, initially underperforms, but is the best in the long run. Likewise, as we vary organizational capabilities, we can observe complex changes: an increase in either search radius or the number of alternatives that are considered in each period is beneficial to the integrated form in the long run. By contrast, the modular form suffers as organizational capabilities are increased along either of these dimensions. Lastly, while the self-governing alliance outperforms the ratified alliance when the number of considered alternatives is high (capability levels B and D), the ratified alliance has higher performance, at least in the short run, when the search radius is high and the number of considered alternatives is low (capability level C).

Insert Figure 5 about here

The results of Patterns 1 and 4 illustrate several points. First, we find initial support for Proposition 1: patterns of interdependence can have a significant impact on the relative value of individual governance modes. Second, once the pattern of interdependence is not simple anymore, the relationship between governance mode and performance is not trivial, especially when one takes into account different levels of organizational capabilities and measures performance at different time points. To gain a better understanding of the results, and to identify

\footnotetext{
${ }^{8}$ Since interdependencies exist within the set of activities each manager controls (e.g., within $\mathrm{N}_{1}$ ), each manager still may get stuck on a local peak within her 'sub-landscape.' $\Lambda$ increase in the search radius reduces the probability that managers will get stranded on such low, local peaks, and hence increases long-run performance .
} 
the underlying mechanisms that create this complex set of findings, it is helpful to return to our conceptual model of coordination and exploration. In particular, we will describe in detail the demands that different patterns of interdependence create with respect to coordination and exploration and how well the different governance modes match these demands. As we will show, the degree to which coordination and exploration demands are matched can help explain observed performance heterogeneity.

\section{Coordination and exploration as underlying mechanisms}

To study the effect of interdependence patterns on the performance created by different governance modes, we focus on how particular patterns differ systematically in where interdependencies occur: between alliance and non-alliance choices; within alliance policy choices; and between the non-alliance choices of the two firms. These three classes of interdependencies create three corresponding dimensions of coordination demands: (1) coordination between the individual firms and the alliance; (2) coordination within the alliance itself; and (3) coordination between the non-alliance activities of Firms 1 and 2. As summarized in Panel A of Table 1, the only coordination required by Pattern 1 is among a few choices within the alliance, i.e., within $\mathrm{A}_{1}$ and within $\mathrm{A}_{2}$. Pattern 2, which contains also interactions between the alliance activities of the individual firms (i.e., between $A_{1}$ and $A_{2}$ ), requires more intra-alliance coordination. Pattern 3 requires additional coordination between the individual firms' and the alliance activities. Finally, Pattern 4 demands coordination between the non-alliance activities for Firms 1 and 2 as well.

Patterns 1 - 4 not only differ in their locations of interdependencies, but also in the number of interdependencies. Generally, the larger the number of interdependencies, the more "rugged" a performance landscape becomes, i.e., the more local peaks it contains (e.g., Levinthal, 1997). (A policy configuration $\boldsymbol{d}$ is a local peak if all policy configurations that differ from $\boldsymbol{d}$ in only one policy choice have lower performance.) The higher the number of local peaks, the higher the risk of getting stranded on a low-performing local peak; and consequently, the higher the level of exploration needed to reach high performance. As a result, the number of local peaks that are contained in a landscape is a good measure for exploration demands. The right-most column of Panel A of Table 1 contains the number of local peaks for each interdependence pattern. As expected, the number of local peaks increases from 18 for Pattern 1 to 315 for Pattern 
4. (For comparison, a landscape with 12 policy choices has $2^{12}=4,096$ possible policy configurations.) In sum, the patterns differ in the types and degree of coordination, as well as the degree of exploration they demand.

We now turn our attention to the different governance modes. Variation across these modes along the four key design dimensions (number of agents; order of decision making; decision evaluation metrics; and oversight and hierarchy) generates substantial differences in the types and degree of coordination. To facilitate comparison with the different types of coordination that are demanded by the different interdependence patterns, Panel B of Table 1 summarizes the coordination that is supplied by the different governance structures along the three coordination dimensions (individual firm-alliance; within alliance; and between Firms 1 and 2).

The modular mode supplies very little coordination along any of the coordination dimensions. Non-alliance activities are completely uncoordinated between the two firms as decisions are made simultaneously and purely independently of one another. Likewise, the modular mode has very little within-alliance coordination. Since own-firm alliance activities are controlled by each firm (for instance Firm 1 controls $d_{5}$ and $d_{6}$ ), a limited amount of coordination is created between at least a subset of alliance activities (i.e., Firm 1 coordinates between $d_{5}$ and $d_{6}$, and Firm 2 between $d_{7}$ and $d_{8}$ ). Similarly, only limited coordination occurs between alliance activities and the non-alliance activities of each firm. For instance, Firm 1 coordinates between $d_{1}-d_{4}$ and $d_{5}$ and $d_{6}$, but ignores the interactions between $d_{1}-d_{4}$ and $d_{7}$ and $d_{8}$.

Within the self-governing alliance, strong coordination is achieved among the alliance activities, since they are all controlled by a single alliance agent. A small amount of coordination also occurs between the non-alliance activities and the alliance activities. This coordination arises from the sequential moves within a given period and from the individual firms' taking into account a portion $(\alpha)$ of the alliance performance in making their decisions. Thus, when firm managers make decisions concerning the non-alliance activities, they would not implement policy changes that (drastically) undermine alliance performance. No coordination, however, is achieved between the non-alliance activities of both firms.

The ratification alliance mode adds more coordination; here, in addition to the coordination sources mentioned for the self-governing alliance mode, the additional ratification step adds greater coordination between the non-alliance policies and the alliance, since the 
alliance is not allowed to implement choices that might be very detrimental to one of the firms. Finally, the integrated mode, with a single decision maker, achieves full coordination across all decisions.

To measure in our simulations the amount of coordination that is provided by the various governance modes given a particular interdependence pattern and organizational capability level, we observe the number of times that a coordination failure occurs. We measure coordination failures as incidents in which total profits decline from the prior period. Thus, in such a period, the various agents implemented policy changes that in their entirety reduced overall profits, a clear form of coordination failure.

We now turn our attention to exploration. Exploration is affected by both the governance structure and the organizational capability level. Different structures create different degrees of exploration by imposing higher or lower levels of decision-making constraints on agents. In the modular case, for example, the two agents act purely independently, without regard to the effects that their actions may have on the other firm's performance. Such independence can result in very high exploration. In contrast, the integrated firm, always having to take all ramifications into account, tends to be much less explorative. Exploration supply for the alliance modes lies in between. The self-governing mode creates exploration through the unfettered alliance agent, who is allowed to move first and implement choices from a purely parochial point of view. The ratified alliance structure, one would expect, creates less exploration. In this case, while the alliance is still allowed to make parochial evaluations of alternatives, the ratification step dampens the exploration the firms engage in. Table 1, Panel C summarizes this discussion.

Insert Table 1 about here

The effects of organizational capabilities on exploration are straightforward at the level of individual agents. An increase in the search radius increases the range of possible alternatives that an agent might consider, and thus increases exploration. Likewise, an increase in the number of alternatives that an agent considers increases, at least in the short run, the area of the landscape an agent might explore. How an increase in exploration at the level of individual agents translates, however, to exploration at the level of the organization can be less straightforward. For instance, as Siggelkow and Rivkin (2006) have shown, increases in exploration at a low-level within a hierarchical organization can backfire and create less exploration for the organization as a whole. 
To measure in our simulations the degree to which exploration is supplied by different combinations of governance structures and organizational capabilities for different interdependence patterns, we create two measures: percent of choices evaluated, and number of sticking points. We construct the percent of choices evaluated by calculating the total number of different contribution values $\left(\mathrm{C}_{\mathrm{i}}\right.$ 's) considered by agents in the system over time, and dividing this by the total number of contribution values that exist for a landscape. (For instance, Pattern 1 involves 144 contribution values while Pattern 4 involves 49,152 contribution values.) The second exploration metric, sticking points, measures the number of points on the landscape from which the firm will not make a move (Rivkin and Siggelkow, 2003). Higher values of this metric suggest a governance structure-capability combination that is less prone to broader exploration.

\section{Optimal governance with varying interdependence}

Armed with a more detailed understanding of exploration and coordination supplies and demands, and with our battery of coordination and exploration measures, we now return to a more in-depth discussion of the Pattern 1 and 4 results. We begin with Pattern 1; Table 2 reports the performance results for Pattern 1 at periods 10 and 200, along with the metrics discussed above for exploration and coordination. We begin by noting that this pattern, being fully decomposable, requires little coordination and exploration. On this pattern, for any given level of organizational capability, all governance modes perform equally well in the long run, reaching the same level of performance over time. There are instances, however, in which performance differs across modes in the short run.

To understand the sources of the performance differences, we turn to the metrics for coordination and exploration. As the right-most column of Table 2 indicates, none of the governance modes experiences any coordination failure on this pattern. As a result, performance variation is solely driven by differences in exploration generated by the different modes. As a matter of fact, the performance ordering of the four governance modes in period 10 , for all levels of organizational capability, is exactly the ordering along the exploration metric percent of choices evaluated by period 10. For instance, for capability level A, this exploration metric is lowest for the integrated mode at $25 \%$, and highest for the self-governing and ratified alliance modes at $40 \%$, with the modular mode in between at $35 \%$. This is consistent with the ordering of performance values at period 10 . 
The performance benefits in early periods for the alliance modes illustrate the benefit of splitting activities among different agents in the system; because the various activities can be easily decomposed in this pattern, a larger number of agents who can work in parallel results in a higher degree of exploration without resulting in coordination failures across activities. In the long run, however, at Period 200, the four governance modes reach the same level of exploration, and indeed the same level of performance.

With this simple pattern of interdependence, increases in organizational capabilities also create expected effects. An increase in the search radius (moving from capability level A to level C) leads primarily to an increase in long-run exploration and, consequently, to higher long-run performance levels. The percent of choices evaluated metric increases from about $45 \%$ in level A to about $81 \%$ for level $\mathrm{C}$; likewise, the number of sticking points decline for all governance modes from about 18 to 2 . At the same time, an increase in the number of alternatives considered (capability levels $\mathrm{A}$ to $\mathrm{B}$, and $\mathrm{C}$ to $\mathrm{D}$ ) results primarily in increased speed with which the various governance modes converge to the long-run performance level. With capability levels B and D, for all governance modes, the measures of exploration and performance are essentially identical between periods 10 and 200 .

Insert Table 2 about here

As we had seen previously, results for Pattern 4, the fully interdependent pattern, are much more complex. Pattern 4 requires a high degree of both coordination and exploration. Moreover, as argued in Table 1, the different governance modes differ widely in both the coordination and exploration that they provide. We begin our discussion of Pattern 4 with capability level A. In this case, in the short run at period 10, the integrated form has the highest performance, followed in order by the ratification, self-governing alliance and modular forms. The coordination failures metric mirrors well our previous discussion of coordination supplied by the various governance modes (recall Table 1, Panel B): the integrated mode provides the highest degree of coordination ( 0 coordination failures), followed by the ratified mode (on average 3.1 coordination failures), the self-governing mode (6.0 failures), and the modular mode (10.3 failures). It is interesting to note that in this case coordination failures predict short-run performance remarkably accurately. Moreover, this finding holds for all capability levels. Even if a firm has higher short-term exploration, coordination appears to trump in the short run. For 
instance, as in Pattern 1, both the ratified and the self-governing modes have higher short-term exploration than the integrated mode due to the parallel search processes that they are able to engage in. However, more search, if uncoordinated, is likely to lead to some changes that are performance detrimental. These changes are particularly harmful in the short run, since firms do not have enough time to potentially undo these maladaptive adjustments. As a consequence, the integrated firm, despite its smaller degree of short-term exploration, outperforms the ratified and self-governing (and modular) modes in the short run.

The explanation of long-run results is more complicated as both coordination and exploration play critical roles. In the long run, firms have to engage in both to have high performance, yet tradeoffs arise. As the exploration and coordination metrics in Table 3 indicate, there is a general tradeoff between exploration and coordination: the modes that create much exploration, such as the modular mode, also create many coordination failures, while the modes that are good at coordination, such as the integrated mode, are less able to create broad exploration.

Coming back to the results for capability level A, we can observe that in the long run the short-run performance results are exactly reversed. In the long run, the modular mode has the highest level of performance, followed by the self-governing alliance, and the ratified and integrated forms. The two long-run exploration measures (percent of choices evaluated at period 200 and the number of sticking points) both confirm our previous discussion of exploration supplied by the various governance modes (recall Table 1, Panel C). For instance, while the integrated mode has 315 sticking points, the modular form only gets stuck on about 84 points. Likewise, the modular form evaluates in 200 periods about 590 different contribution values ( $1.2 \%$ of all possible) while the integrated form looks at only $246(0.5 \%)$. The differences in exploration are reflected in performance, as in this case, the long-run exploration metrics predict well the performance ordering of the governance modes.

This direct match between long-run exploration and long-run performance does not hold, however, for all levels of organizational capability. As organizational capabilities are increased, their effects on coordination failures and exploration differ across governance modes. Consequently, the relative balance of exploration and coordination that is supplied by each mode changes. For instance, an increase in the search radius or the number of alternatives is an unambiguous good for the integrated mode. Coordination failures are unaffected (they stay at 
zero) while exploration increases. As a result, performance increases as capabilities increase. For all the other governance modes, however, increases in organizational capabilities are not unambiguously beneficial. Generally, an increase in organizational search capabilities increases exploration but also increases coordination failures. The more broadly managers search and the more alternatives they evaluate, the more likely it is that at least one manager (within the firms or within the alliance) will implement a change that is performance detrimental for the other agents in the system. For instance, for the self-governing alliance, coordination failures increase from 6 (with Capability Level A) to 22 (for Capability Levels B and C) to 32 (for Capability Level D). Similar patterns can be observed for the ratification and the modular modes. The impact of increasing search capabilities at the level of the agents on long-run firm performance is, hence, ambiguous. For instance, while the modular mode increases its exploration dramatically between Capability Levels A and D (the number of sticking points falls by a factor of 10 and the number of choices evaluated increase by a factor of 10 ), its coordination failures also increase by a factor of 7. As we had seen in the short-run results, if coordination failures are too prevalent, exploration does not yield performance benefits: while it is helpful to search more broadly, if the outcome of the search is uncoordinated, firms' performances will suffer. As a result, the long-run performance of the modular mode actually decreases from 0.842 to 0.747 as organizational capabilities are increased from Level A to Level D.

Insert Table 3 about here

In sum, the results highlight several key points. First, as suggested by Proposition 3, the match between exploration and coordination demands and supply helps explain the performance outcomes of the various governance modes. In Pattern 1, in which little coordination was needed, performance differences among modes is well explained, both in the short and the long run, by the degree of exploration that is supplied. In Pattern 4, in which coordination demands are very high, coordination supply plays a pivotal role in explaining performance. For short-run performance, it tracks performance perfectly. For long-run performance, if exploration is very low (as with capability level A), exploration can trump coordination in explaining performance differences; otherwise, coordination again appears to be more important in explaining performance. Second, in the absence of many interdependencies, increases in organizational search capabilities are beneficial for all governance modes. In the presence of rich interactions, 
however, increases in organizational search capabilities can backfire. Even though increases in organizational capabilities may have counterintuitive effects on performance, their effects can be explained by their consequences on exploration and coordination. While exploration increases with greater organizational search capabilities, coordination failures increase as well. Consequently, performance can suffer.

Results for Patterns 2 and 3 can be similarly explained. However, rather than discussing each simulation separately, we summarize our results compactly by reporting (in Table 4) the results of OLS regressions of performance (sum of Firm 1 and Firm 2) on our measures of exploration (percent of choices evaluated) and coordination (coordination failures). The underlying dataset pools observations at either period 10 (short-run) or 200 (long-run) for the four patterns, four governance modes and four capability levels. We thus have 640,000 observations for the short-run and the long-run regressions ( $4 \times 4 \times 4 \times 10,000$ simulations). To control for pattern-level influences on performance we include pattern dummies for Patterns 2-4 (thus Pattern 1 is the baseline); to examine the varying role of coordination and exploration as the degree of interdependence changes we include interaction effects for these dummies with the coordination and exploration measures. Since there are no coordination failures on Pattern 1, coordination is only interacted with Pattern 3 and Pattern 4, so that Pattern 2 is the baseline in this case. For a given pattern, the effect of either coordination or exploration is thus captured by the sum of the main effect and the pattern interaction.

The results in Table 4 confirm more systematically a number of observations we had made in our prior discussion. First, as interdependencies increase, coordination becomes increasingly important: the interaction of coordination failures with the pattern dummies, for example, is significantly greater in magnitude for Pattern 4 than with Pattern 3 . With increasingly dense interactions, coordination becomes paramount in explaining performance. Second, exploration is always important, but becomes less so with higher degrees of interaction. These results are true for both the short- and long-run, with coordination even more important for higher-interaction patterns in the long-run. ${ }^{9}$ Figure 6 illustrates the economic significance of these regression results, graphing the magnitude of the performance change associated with a one

\footnotetext{
${ }^{9} \Lambda$ ll coefficients are significant with $\mathrm{p}<0.001$; in addition, for each specification, all coefficients are significantly different from one another with $\mathrm{p}<0.001$, with the exception of the interaction terms $P 3^{*}$ exploration and $P 4^{*}$ exploration for period 10 , where the significance of the difference between these two variables is with $\mathrm{p}<0.05$.
} 
standard deviation change in either coordination or exploration. ${ }^{10}$ As this figure illustrates, for denser patterns coordination can become even more critical than exploration.

This last result is noteworthy. Most research on the value of exploration has stressed the positive relationship between the value of exploration and the degree of interdependency (e.g., Rivkin and Siggelkow, 2007). While we confirm this relationship, we find that in an interorganizational setting coordination may actually become even more important than exploration. Exploration per se, when not coordinated, can backfire.

Insert Table 4 and Figure 6 about here

\section{DISCUSSION AND CONCLUSION}

In this paper we have sought to better understand how modes of governance affect the performance of firms in alliance relationships. While collaboration is an important component of firm strategy, and a growing body of work has focused on determinants of governance choice in this setting, there is limited empirical evidence concerning the link between mode choice and firm performance. We drew from a body of work that has used simulation methodologies to address issues central to strategy and organization design. In the remainder of this section we review our core results and theoretical predictions; discuss assumptions made in our model; and end with a discussion of how our study relates to and contributes to the literature in this area.

\section{Results and theoretical predictions}

We begin by reviewing our core results, noting how they relate to the propositions which were derived from the prior literature, and offering a set of specific predictions for future work. In many cases our analysis has enabled us to uncover additional nuance relative to the propositions that can help guide future theoretical and empirical research. Beginning with Proposition 1, we find that the pattern of interdependence among the activities of firms engaged in an alliance does have a crucial impact on the optimal governance structure. In addition to confirming this prediction, we also find that the time horizon over which firms seek to maximize their

\footnotetext{
${ }^{10}$ For ease of comparison, the deviation decrease in coordination failures negative of the coordination failure effects are shown; thus the figure shows the effect of a one standard deviation increase in exploration, and a one standard.
} 
performance has an important effect on optimal governance as well: as we saw with the fully interdependent pattern and capability level A (Figure 5), governance modes that create high short-term performance may not yield high long-term performance, and vice versa. Thus, knowing the pattern of interdependence alone may not suffice to decide on the optimal governance mode.

Consistent with Propositions $2 \mathrm{a}$ and $2 \mathrm{~b}$, we find that the need for and supply of coordination and exploration is affected by the pattern of interdependence, governance modes and organizational search capabilities. We discover considerable subtlety, however, on the supply side, as governance choice and search capabilities interact with one another. As we saw in Table 3 , increases in organizational search capabilities can increase exploration but also coordination failures. Moreover, the degree to which search capabilities increase coordination failures is strongly mediated by the governance mode. For instance, while the integrated mode was unaffected, coordination failures in the modular mode soared with increases in organizational search capabilities. This interaction can make simple predictions as to which governance mode provides more coordination difficult. For instance, while the degree of coordination failures generally followed the trend we anticipated in Panel B of Table 1 (most coordination is provided by the integrated mode, followed by the ratified alliance, the self-governing alliance, and the modular mode), we found situations in which the ratified alliance actually creates more coordination failures than the self-governing alliance. This happens in particular when interdependencies are numerous and agents evaluate many alternatives (see Table 3, capability levels B and D). ${ }^{11}$

Finally, consistent with the arguments leading to Proposition 3, we find that firm performance in an alliance relationship improves when coordination and exploration needs are matched with coordination and exploration supplied. Our results, however, also reveal that the match on the coordination and the exploration dimension is not always equally important. As the

\footnotetext{
"The reason for why the ratified alliance has more coordination failures in this case than the self-governing alliance is quite subtle. Recall, in the ratified alliance, the managers of the non-alliance activities move first. Given high interdependency and many alternatives considered, it is likely that at least one manager will find and implement a change that is performance enhancing for her own firm, but potentially performance destroying for the other firm. In the self-governing alliance, the alliance moves first. In this case, the alliance achieves higher performance (since they can optimize parochially and do not need ratification). This higher performance increases the bar for the non-alliance managers for finding a better alternative. (Recall, non-alliance managers take $1 / 2$ of the alliance performance into account in making evaluations). $\Lambda \mathrm{s}$ a result, in this case, non-alliance managers are less likely to find a (parochially) performance enhancing move which, given the high interdependency, could undermine the performance of the other firm.
} 
degree of interdependence increases, the value of having a good match on the coordination dimension increases. For very high levels of interdependence, coordination can actually trump exploration. Even though high levels of interdependence require a high degree of exploration, unless this exploration is tied to coordination, it can be ineffective.

As discussed at the beginning of this paper, empirical results concerning the performance impact of alliances are mixed; moreover, there exists only limited empirical evidence examining the performance implications of alternate modes of governance. The results of our model suggest that clear-cut empirical results may require a greater focus on the interaction of factors such as interdependence, capabilities and governance mode. In particular, our results offer three specific predictions that could guide future empirical work:

(1) In the absence of strong organizational search capabilities, when activity interdependence is pervasive, the performance benefit of a fully-integrated alliance governance mode relative to less-integrated modes will decline over time.

(2) When activity interdependence is pervasive, in alliances with weak coordinating mechanisms, firm performance may decline as firms' search capabilities become stronger.

(3) When activity interdependence is pervasive, the relative importance of selecting highcoordination governance modes as compared to high-exploration modes will increase.

\section{Simulation model assumptions}

We next discuss several assumptions embedded in our model and elaborate on the implications for our results (and for future extensions) of relaxing some of these assumptions. First, we modeled an alliance situation with two firms. It is not uncommon, however, for alliances to involve more than two firms. In such cases, we would expect that similar issues of coordination and exploration would come into play. The main question, then, is how firms can design a set of governance structures that take into account the complexities associated with having a greater number of involved parties. For instance, an appropriate methodology for ratifying joint decisions in such a setting would likely involve a more complex set of rules given the larger number of players. At the same time, we would expect that the core issue is likely to be the same as in a twofirm setting: how can the need for coordination and exploration arising from the pattern of inter- 
firm interdependence be matched with the supply of coordination and exploration arising from inter-firm governance of decision-making and firm capabilities?

A second modeling assumption involves the portion of the alliance profit each firm takes into account in making decisions (the parameter $\alpha$ in our model). In our analysis, we have assumed that both firms put equal weight on alliance performance. One might imagine, however, situations in which the alliance is considered of greater importance by one firm than by the other. How are our results affected in such a situation? We take a first cut at exploring this by examining our results in the case where Firm 1 has $\alpha=0.75$ and Firm 2 has $\alpha=0.25$ (for the alliance modes). Re-running our model on Patterns 1 and 4, and focusing on the two alliance modes (self-governing and ratified), we find that, as expected, on Pattern 1 there are no significant differences between the original, 'balanced' alliance results and the alternative, 'asymmetric' alliance results (due to the lack of interdependencies between the alliance and nonalliance activities). With Pattern 4, however, we find an interesting set of results: alliance asymmetry reduces the performance of Firm 1 (with the 0.75 weight), while increasing the performance of Firm 2, for both the self-governing and ratified modes. The firm with a higher emphasis on the alliance suffers largely because the other firm now has a stronger incentive to implement choices that improve performance of its non-alliance activities $\left(\mathrm{N}_{2}\right)$ but that are detrimental to the alliance and hence to the other firm. (Since $\alpha$ is low, Firm 2 bears less of the negative externality it imposes onto the alliance.) This parochial behavior can lead to situations in which even joint profits are lower than in the symmetric case. These results raise the question for future research of how firms can create modes with effective coordination when firms differ in the degree to which they consider the joint alliance to be important.

A third modeling assumption relates to the implications of pre-defining a task allocation structure. Because we pre-specify the tasks that comprise the alliance, we are effectively making the choice of alliance scope exogenous. This choice, however, is likely intertwined with a host of other issues related to interdependence, firm capabilities and governance mode. We conducted several robustness analyses to better understand the implications of thinking about alliance boundaries in this way. The task decomposition we have used in this paper has been a 4-4-4 split between Firm 1, the Alliance and Firm 2. We evaluated two alternative task decomposition structures: a 5-2-5 and a 3-6-3 structure, on which we examined the results of the self-governing and ratified alliance modes. The results suggest that the alliance boundary issue can be explained 
in connection with the governance structures: the results of the 5-2-5 structure closely resemble the modular results, while the 3-6-3 structure creates results that tend to resemble those of the integrated mode. Thus, while the choice of boundaries may in reality be an endogenous consideration for firms, we can think about these as more continuous versions of the governance structures. The modes we evaluate, therefore, represent discrete points among the continuum of choices available to firms, with task allocation being subsumed as an issue within the governance structure decision.

Lastly, we should note that our findings have parallels with results from prior efforts using quite different simulation methods to address organizational issues. Burton and Obel (1980; 1984), for example, utilize a decomposed linear programming methodology (Dantzig (1963); Baumol and Fabian (1964)) to address intra-firm organization issues. They find that firm performance under alternate divisional forms (e.g., M-form vs. U-form) is influenced by the degree of decomposability of the firm's underlying technology. In particular, their results suggest that the benefits of the more decentralized M-form structure are more apparent for more nearly decomposable technologies. This relates to our own finding, where on Pattern 1, which is fully decomposable, the more decentralized 'ratification' mode performs better than the more centralized 'integrated' mode (with the opposite generally true on the less decomposable Pattern 4). It is reassuring to note that different modeling approaches can result in parallels such as these. On the other hand, different approaches can also lead to new insights, as our results linking variation in interdependencies of various types (within and across firms and their alliance activities) with alternate alliance governance structures suggests.

\section{Contributions and implications}

Our study has a number of implications for theory and future research in this area. The observation that coordination challenges can trump exploration in inter-organizational settings underscores the importance of evaluating the contingent implications of interdependence when structuring cooperative relationships. This is consistent with Gulati and Singh's (1998) discussion of coordination as a relevant concern when structuring alliance governance. Moreover, because we abstract away from the technology and industry-related factors that underlie transaction costrelated considerations of appropriability (e.g., Pisano, 1989; Oxley, 1997) we can focus more specifically on identifying the sources of coordination and exploration supply, allowing a more 
targeted approach to understanding the tradeoffs associated with governance mode design. For example, while some prior work has drawn on arguments related to capabilities and interdependence in discussing the determinants of governance mode, much of this work has utilized fairly broad proxies for hierarchical controls such as the use of equity (e.g., Colombo, 2003). Having a more contingent view of the potential implications of specific governance mode design considerations (as we attempt to do in this paper) can enable more targeted research approaches.

A core set of results in this study relates to the ways in which governance structure interacts with organizational search capabilities. These results are particularly intriguing given the attention paid to the role of firm-level factors such as alliance capabilities in recent studies. For example, Kale et al. (2002), building on the idea that greater alliance experience can have positive performance effects (Anand and Khanna, 2000), discuss the role of a 'dedicated alliance function' in capturing and managing alliance-relate knowledge, suggesting that such a function can enable the development of alliance capabilities through learning and evolutionary processes (March, 1991; Nelson and Winter, 1982). In much the same spirit, Zollo et al. (2002) develop the idea of inter-organizational routines, which also follow a similar evolutionary path. Our concept of organizational search capabilities shares a number of features with these various concepts: they are assets tied to the firm and developed over time that endow firm agents with superior evaluation capabilities in the context of inter-organizational relationships. Whereas prior studies have generally stressed the positive relationship between alliance capabilities and firm performance, our analysis suggests that there are contingencies under which investments in the development of these capabilities may actually backfire.

This paper also contributes to the broader conversation around the performance consequences of inter-organizational relationships. Various streams of prior work have examined the effects of alliances on different metrics of firm performance, looking at outcomes such as firm survival (e.g., Baum and Oliver, 1991), innovation output (e.g., Shan et al., 1994) and stock market valuation (Das et al., 1998). While these studies generally find positive effects, albeit with a range of contingencies, other studies paint a more mixed view, for example when comparing inter-organizational relationships with firm capabilities with respect to their impact on performance (e.g., Lee et al., 2001). Much of the variance in alliance-related firm performance outcomes is likely due to partner and inter-firm characteristics (e.g., Stuart, 2000); by illustrating 
how factors such as search capabilities and interdependence can influence the governanceperformance link, our study can shed new light on this area, with future work focused more specifically on empirically testing the predictions of our model.

A key aim of this paper has been to develop a set of insights that can be used to guide future empirical work. In this context, the use of factors such as inter-organizational patterns of interdependence does increase the burden of collecting empirical data that is more fine-grained and complex. At the same time, however, the simulation results can help generate more refined hypotheses that have the opposite effect of simplifying the data collection task. With more specific priors (e.g., in more interdependent settings, modes that enable greater coordination are preferred to modes that enable greater exploration), future work can explore the governance implications of inter-organizational collaboration in a more targeted way using empirical and case-based studies. 


\section{REFERENCES}

Aggarwal VA, Hsu DH. 2009. Modes of cooperative R\&D commercialization by start-ups. Strategic Management Journal 30(8): 835-864.

Anand BN, Khanna T. 2000. Do firms learn to create value? The case of alliances. Strategic Management Journal 21(3): 295-315.

Baum JAC, Oliver C. 1991. Institutional linkages and organizational mortality. Administrative Science Quarterly 36(2): 187-218.

Baumol WJ, Fabian T. 1964. Decomposition, pricing for decentralization and external economics. Management Science 11(1): 1-32.

Burton RM, Obel B. 1980. A computer simulation test of the $\mathrm{m}$-form hypothesis. Administrative Science Quarterly 25(3): 457-466.

Burton RM, Obel B. 1984. Designing efficient organizations: modeling and experimentation. Elsevier Science Publishers BV: Amsterdam, The Netherlands.

Burton RM, Obel B. 1995. Strategic organizational diagnosis and design: developing theory for application. Kluwer Academic Publishers: Norwell, MA.

Colombo MG. 2003. Alliance form: a test of the contractual and competence perspectives. Strategic Management Journal 24(12): 1209-1229.

Cyert RM, March JG. 1963. A behavioral theory of the firm. Prentice Hall: New Jersey, USA.

Dantzig GB. 1963. Linear programming and extensions. Princeton University Press: New Jersey, USA.

Das S, Sen PK, Sengupta S. 1998. Impact of strategic alliances on firm valuation. Academy of Management Journal 41(1): 27-41.

Dyer JH, Kale P, Singh H. 2004. When to ally and when to acquire. Harvard Business Review 82(78): $108-115$.

Dyer JH, Singh H. 1998. The relational view: cooperative strategy and sources of interorganizational competitive advantage. Academy of Management Review 23(4): 660-679.

Galbraith JR. 1977. Organization design. Addison-Wesley: Reading, MA.

Gulati R. 1998. Alliances and networks. Strategic Management Journal 19(4): 293-317.

Gulati R, Lawrence PR, Puranam P. 2005. Adaptation in vertical relationships: beyond incentive conflict. Strategic Management Journal 26(5): 415-440.

Gulati R. Singh H. 1998. The architecture of cooperation: managing coordination costs and appropriation concerns in strategic alliances. Administrative Science Quarterly 43(4): 781-814.

Hennart J. 1993. Explaining the swollen middle: why most transactions are a mix of "market" and hierarchy. Organization Science 4(4): 529-547.

Kale P, Puranam P. 2004. Choosing equity stakes in technology-sourcing relationships: an integrative framework. California Management Review 46(3): 77-99. 
Kale P, Dyer JH, Singh H. 2002. Alliance capability, stock market response, and long-term alliance success: the role of the alliance function. Strategic Management Journal 23(8): 747-767.

Kauffman S. 1993. The origins of order: self-organization and selection in evolution. Oxford University Press: New York, NY.

Klein B, Crawford RG, Alchian AA. 1978. Vertical integration, appropriable rents, and the competitive contracting process. Journal of Law and Economics 21(2): 297-326.

Lawrence PR, Lorsch JW. 1967. Organization and environment. Harvard Business School Press, Cambridge, MA.

Lee C, Lee K, Pennings JM. 2001. Internal capabilities, external networks, and performance: a study on technology-based ventures. Strategic Management Journal 22(6-7):615-640

Leiblein MJ, Miller DJ. 2003. An empirical examination of transaction- and firm-level influences on the vertical boundaries of the firm. Strategic Management Journal 24(9): 839-859.

Lenox MJ, Rockart SF, Lewin AY. 2006. Interdependency, competition, and the distribution of firm and industry profits. Management Science 52(5): 757-772.

Levinthal D. 1997. Adaptation on rugged landscapes. Management Science 43(7): 934-950.

March JG. 1991. Exploration and exploitation in organizational learning. Organization Science 2(1): 71-87.

Mayer KJ, Salomon RM. 2006. Capabilities, contractual hazards, and governance: integrating resource-based and transaction cost perspectives. Academy of Management Journal 49(5): 942-959.

Mintzberg H. 1979. The structuring of organizations. Prentice Hall: Englewood Cliffs, NJ.

Nelson RR, Winter SG. 1982. An evolutionary theory of economic change. Belknap Press: Cambridge, MA.

Oxley JE. 1997. Appropriability hazards and governance in strategic alliances: a transaction cost approach. Journal of Law, Economics, \& Organization 13(2): 387-409.

Pisano GP. 1989. Using equity participation to support exchange: evidence from the biotechnology industry. Journal of Law, Economics, \& Organization 5(1): 109-126.

Porter M. 1996. What is strategy? Harvard Business Review 74(6): 61-78.

Reuer JJ. 2004. Strategic alliances: theory and evidence. Oxford University Press: New York, NY.

Rivkin J, Siggelkow N. 2003. Balancing search and stability: interdependencies among elements of organizational design. Management Science 49(3): 290-311.

Rivkin J, Siggelkow N. 2007. Patterned interactions in complex systems: implications for exploration. Management Science 53(7): 1068-1085.

Robinson D, Stuart T. 2007. Financial contracting in biotech strategic alliances. Journal of Law and Economics 50(3): 559-595. 
Sampson R. 2004. The cost of misaligned governance in R\&D alliances. Journal of Law, Economics and Organization 20(2): 484-526.

Schelling TC. 1960. The strategy of conflict. Harvard University Press: Cambridge, MA.

Shan W, Walker G, Kogut B. 1994. Interfirm cooperation and startup innovation in the biotechnology industry. Strategic Management Journal 15(5): 387-394.

Siggelkow N. 2001. Change in the presence of fit: the rise, the fall, and the renaissance of Liz Claiborne. Academy of Management Journal 44(4): 838-857.

Siggelkow N. 2002. Evolution toward fit. Administrative Science Quarterly 47(1): 125-159.

Siggelkow N, Rivkin J. 2005. Speed and search: designing organizations for turbulence and complexity. Organization Science 16(2): 101-122.

Siggelkow N, Rivkin J. 2006. When exploration backfires: unintended consequences of multi-level organizational search. Academy of Management Journal 49(4): 779-795.

Simon HA. 1945. Administrative behavior. The Free Press: New York, NY.

Simon HA. 1996. The sciences of the artificial. MIT Press: Cambridge, MA.

Stuart TE. 2000. Interorganizational alliances and the performance of firms: a study of growth and innovation rates in a high-technology industry. Strategic Management Joumal 21(8): 791-811.

Thompson JD. 1967. Organizations in action. McGraw-Hill: New York, NY.

Tushman ML, Nadler DA. 1978. Information processing as an integrating concept in organizational design. Academy of Management Review 3(3): 613-624.

Villalonga B, McGahan AM. 2005. The choice among acquisitions, alliances, and divestitures.

Strategic Management Journal 26(13): 1183-1208.

Volberda HW. 1996. Toward the flexible form: how to remain vital in hypercompetitive environments. Organization Science 7(4): 359-374.

Williamson OE. 1975. Markets and hierarchies: analysis and antitrust implications. The Free Press: New York, NY.

Zollo M, Reuer JJ, Singh H. 2002. Interorganizational routines and performance in strategic alliances. Organization Science 13(6): 701-713. 
Figure 1

Conceptual model: governance mode, capabilities and interdependence

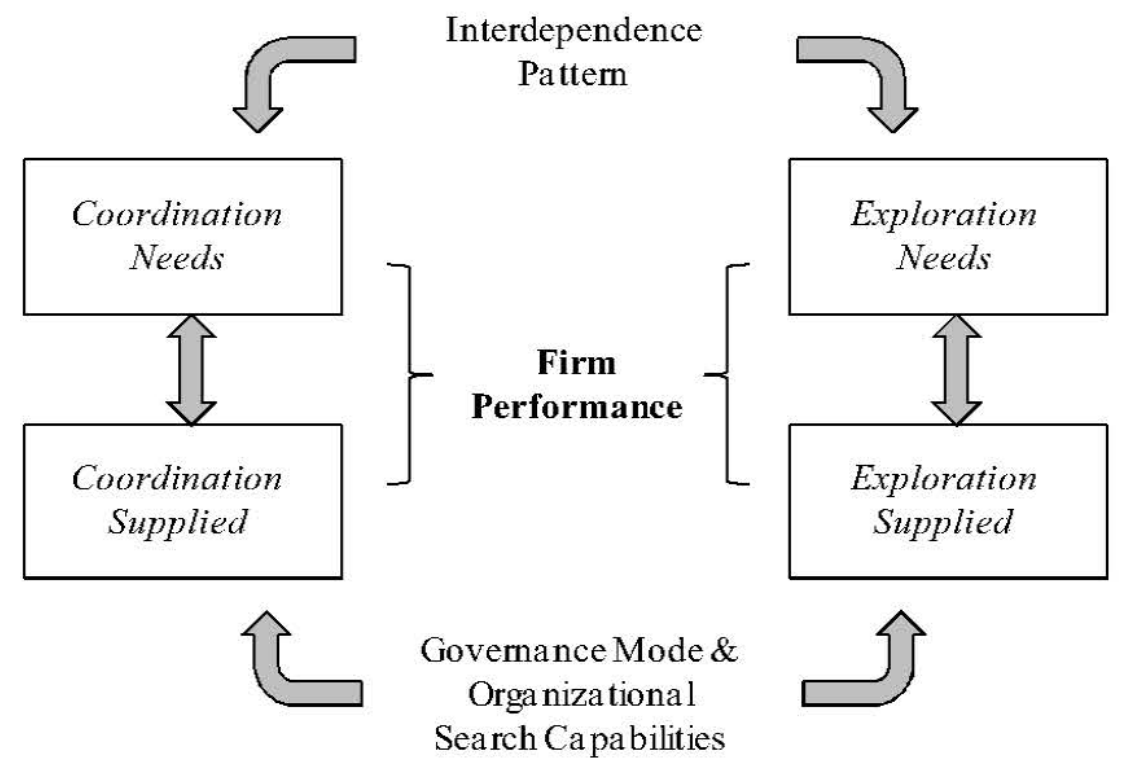


Figure 2

Inter-firm interdependence

\section{A. Interaction matrix example}

Firm 1

Firm 2

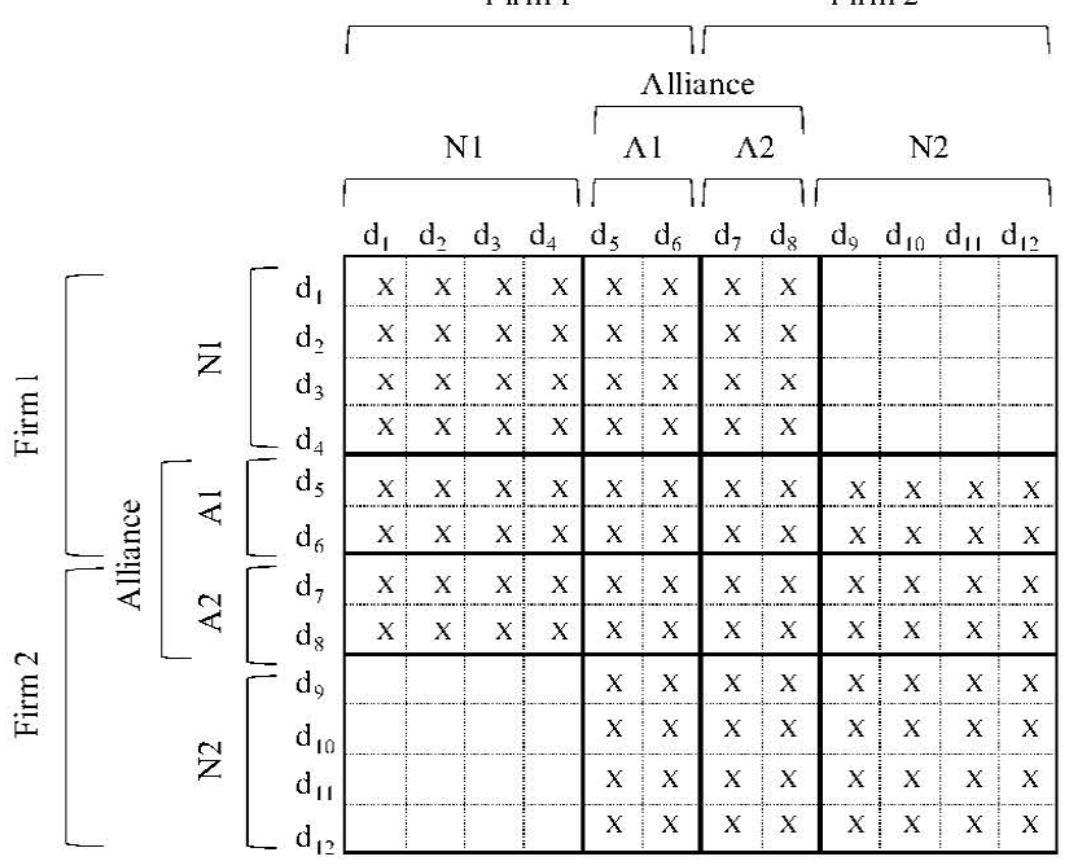

\section{B. Patterns of interdependence}

Pattern 1:

"Fully Decomposable"

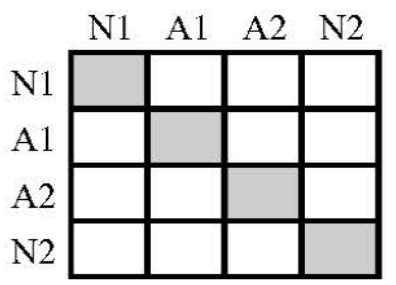

Pattern 3:

"Firm-Alliance Interaction"

\begin{tabular}{|c|c|c|c|}
\hline N1 & $\mathrm{Al}$ & $\mathrm{A} 2$ & $\mathrm{~N} 2$ \\
\hline N1 & & & \\
\hline 1 & & & \\
\hline & & & \\
\hline & & & \\
\hline
\end{tabular}

Pattern 2:

"Pure Alliance Interaction"

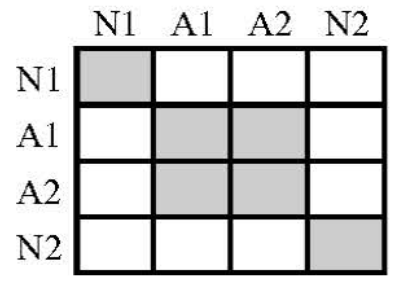

Pattern 4:

"Full Interdependence"

\begin{tabular}{c|l|l|l|l|}
\multicolumn{1}{c}{ N1 } & A1 & A2 & N2 \\
\cline { 2 - 5 } N1 & & & & \\
\cline { 2 - 5 } A1 & & & & \\
A2 & & & & \\
\cline { 2 - 5 } N2 & & & & \\
\cline { 2 - 6 } & & &
\end{tabular}


Figure 3

Summary of governance structures

\begin{tabular}{|c|c|c|c|c|}
\hline $\begin{array}{l}\text { Governance } \\
\text { Structure }\end{array}$ & $\begin{array}{l}\text { Agents and } \\
\text { Policies } \\
\text { Controlled }\end{array}$ & $\begin{array}{l}\text { Decision Making } \\
\text { Sequence }\end{array}$ & $\begin{array}{l}\text { Metrics for } \\
\text { Evaluating Decisions }\end{array}$ & $\begin{array}{l}\text { Oversight and } \\
\text { Hierarchy }\end{array}$ \\
\hline $\begin{array}{l}\text { Modular } \\
\text { (MOD) }\end{array}$ & $\begin{array}{l}\text { Two Agents } \\
\text { Control F1 and } \\
\text { F2, respectively }\end{array}$ & $\begin{array}{l}\text { Firms } 1 \text { and } 2 \\
\text { (simultaneously) }\end{array}$ & $\begin{array}{l}\text { Own-firm profit, } \\
\text { F1 and F2 }\end{array}$ & None \\
\hline $\begin{array}{l}\text { Self-Governing } \\
\text { Alliance } \\
\text { (SGA) }\end{array}$ & $\begin{array}{l}\text { Three Agents } \\
\text { Control N1, } \\
\text { A1-A2, and N2, } \\
\text { respectively }\end{array}$ & $\begin{array}{l}\text { 1. Alliance } \\
\text { 2. Firms } 1 \text { and } 2 \\
\text { (simultaneously } \\
\text { with respect to } \\
\text { N1 and N2) }\end{array}$ & $\begin{array}{l}\text { Alliance profit for A } \\
\text { Own-firm profit plus } \\
\text { portion }(\alpha) \text { of alliance } \\
\text { profit for } F 1 \text { and } F 2\end{array}$ & None \\
\hline $\begin{array}{l}\text { Ratified } \\
\text { Alliance } \\
\text { (RAT) }\end{array}$ & $\begin{array}{l}\text { Three Agents } \\
\text { Control N1, } \\
\text { A1-A2, and N2, } \\
\text { respectively }\end{array}$ & $\begin{array}{l}\text { 1. Firms } 1 \text { and } 2 \\
\text { (simultaneously } \\
\text { with respect to } \\
\mathrm{N} 1 \text { and N2) } \\
\text { 2. Alliance } \\
\text { 3. Firms } 1 \text { and } 2 \\
\text { ratify alliance } \\
\text { proposals }\end{array}$ & $\begin{array}{l}\text { Alliance profit for A } \\
\text { Own-firm profit plus } \\
\text { portion }(\alpha) \text { of alliance } \\
\text { profit for } F 1 \text { and } F 2\end{array}$ & $\begin{array}{l}\mathrm{F} 1 \text { and } \mathrm{F} 2 \text { must } \\
\text { ratify alliance } \\
\text { proposals }\end{array}$ \\
\hline $\begin{array}{l}\text { Integrated } \\
\text { (INT) }\end{array}$ & $\begin{array}{l}\text { One Agent } \\
\text { Controls all policy } \\
\text { choices }\end{array}$ & $\begin{array}{l}\text { Single decision } \\
\text { maker }\end{array}$ & $\begin{array}{l}\text { Own-firm profit, } \\
\text { combining F1+F2 }\end{array}$ & $\begin{array}{l}\text { Implicit full } \\
\text { oversight }\end{array}$ \\
\hline
\end{tabular}


Figure 4

Performance levels of four governance modes: interdependence pattern 1

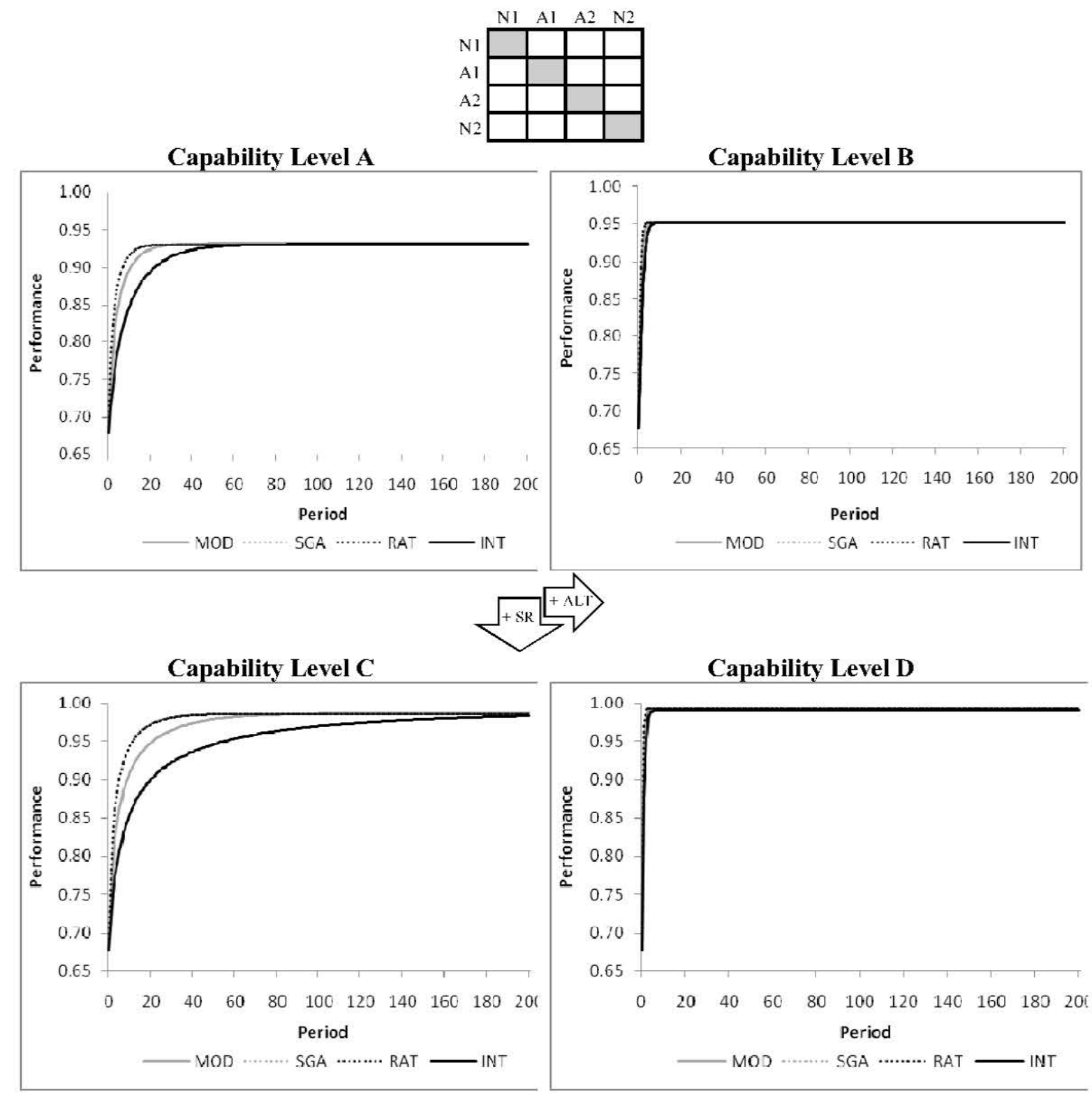

These figures graph performance (vertical axis) for the two-firm system over time periods 0 to 200 (horizontal axis) for the four governance modes on Interdependence Pattern 1 (fully decomposable), with varying levels of organizational capabilitics. Each point on cach line represents the average of 10,000 simulation runs. MOD, SGA, RAT and INT refer to the modular, self-governing alliance, ratified alliance, and integrated forms, respectively. 
Figure 5

Performance levels of four governance modes: interdependence pattern 4

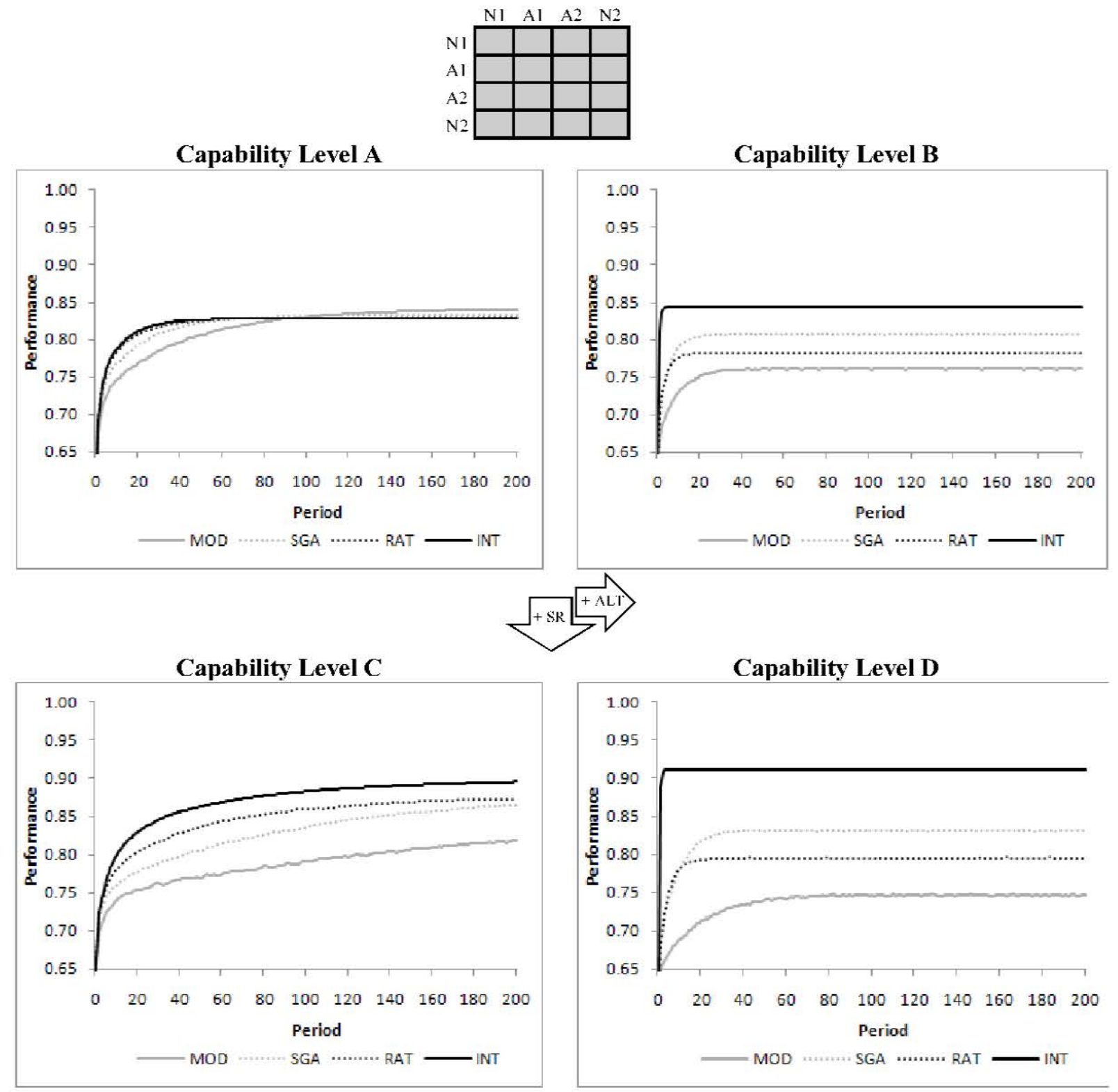

These figures graph performance (vertical axis) for the two-firm system over time periods 0 to 200 (horizontal axis) for the four governance modes on Interdependence Pattern 4 (full interdependence), with varying levels of organizational capabilitics. Each point on each line represents the average of 10,000 simulation runs. MOD, SGA, RAT and INT refer to the modular, self-governing alliance, ratified alliance, and integrated forms, respectively. 
Figure 6

Magnitude of coordination and exploration effects

Performance impact, period 10:

Effect of a one standard deviation change in coordination or exploration

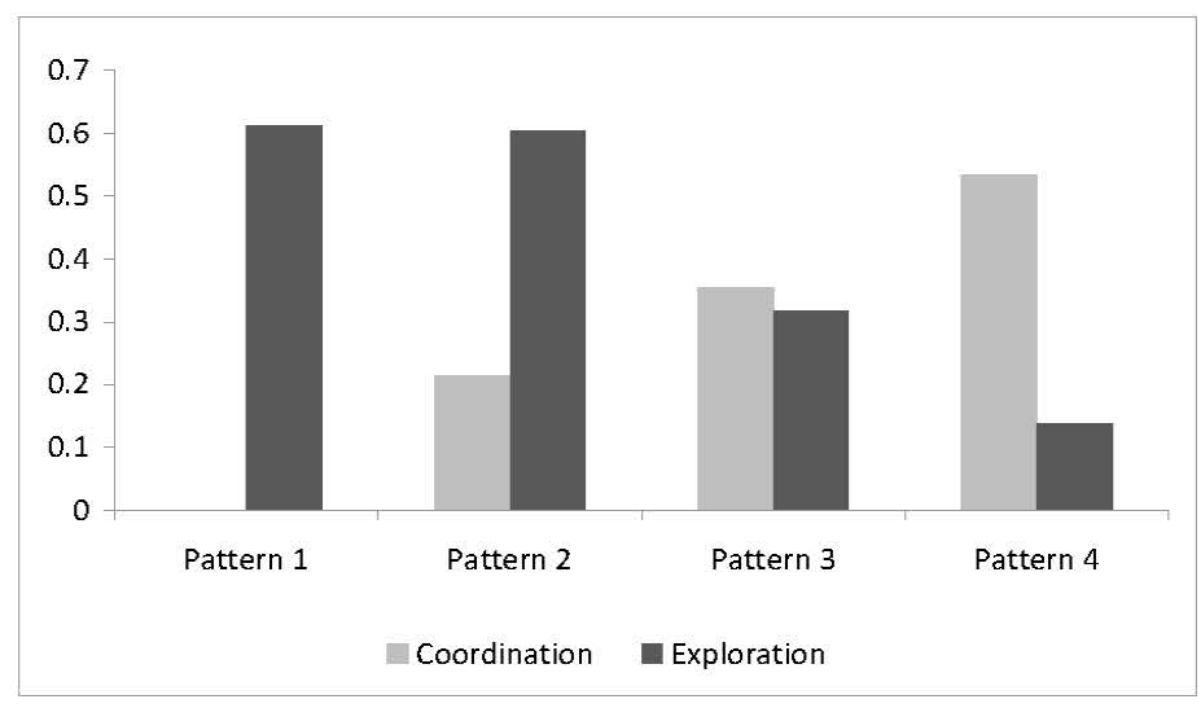

Performance impact, period 200:

Effect of a one standard deviation change in coordination or exploration

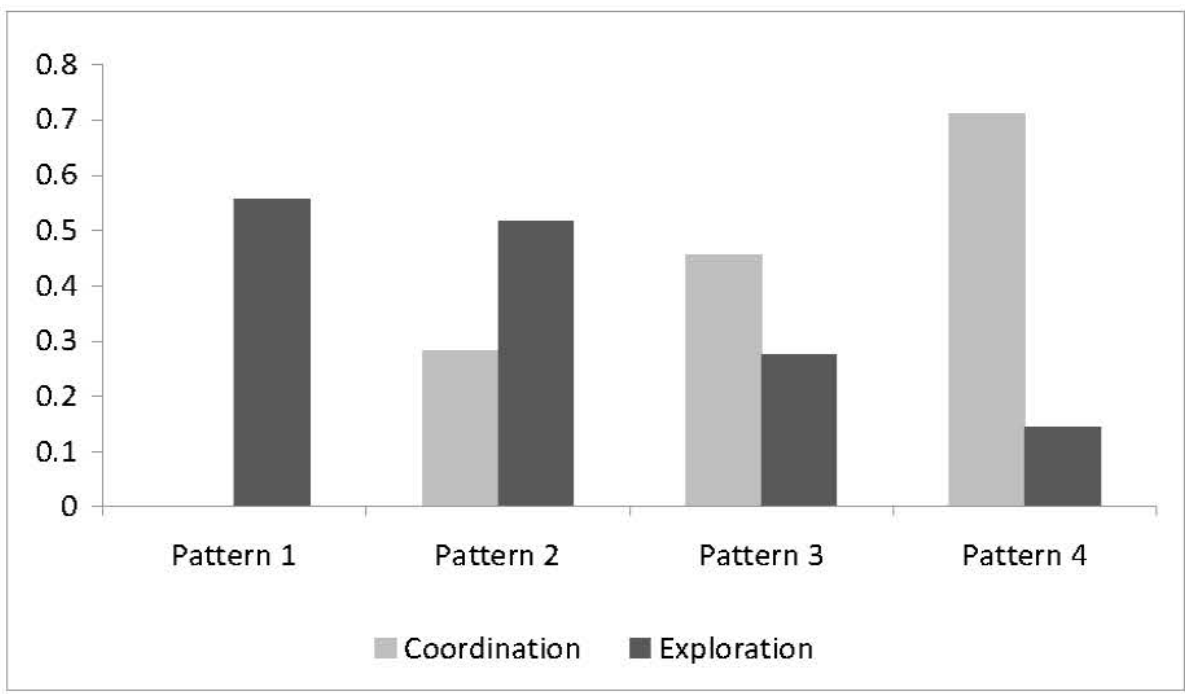

These figures show the change in performance associated with a one standard deviation change in coordination or exploration. Values are calculated using the estimated cocfficients from Table 5 cvaluated at the mean value of coordination (coordination failures) and exploration (percent of choices evaluated) for each pattern. Coordination values shown represent the negative of the coordination failures effect to facilitate exposition. 
Table 1

Demand and supply of coordination and exploration

A. Level of coordination and exploration demanded by the interdependence pattern

\begin{tabular}{|c|c|c|c|c|}
\hline & \multicolumn{3}{|c|}{ Coordination Demanded } & \multirow{2}{*}{$\begin{array}{c}\text { Exploration } \\
\text { Demanded } \\
\text { (Number of } \\
\text { Local Peaks) }\end{array}$} \\
\hline & $\begin{array}{c}\text { Between Firms 1,2 } \\
\text { and Alliance }\end{array}$ & Within Alliance & Between Firms 1, 2 & \\
\hline Pattern 1 & None & Little & None & 18 \\
\hline Pattern 2 & None & High & None & 35 \\
\hline Pattern 3 & High & High & None & 198 \\
\hline Pattern 4 & High & High & High & 315 \\
\hline
\end{tabular}

\section{B. Level of coordination supplied by governance modes}

\begin{tabular}{|lcccl|}
\hline & $\begin{array}{c}\text { Between } \\
\text { Firms 1,2 } \\
\text { and Alliance }\end{array}$ & $\begin{array}{c}\text { Within } \\
\text { Alliance }\end{array}$ & $\begin{array}{c}\text { Between } \\
\text { Firms 1,2 }\end{array}$ & \multicolumn{1}{c|}{$\begin{array}{c}\text { Sources of } \\
\text { Coordination Supply }\end{array}$} \\
\hline MOD & Low & Low & None & $\begin{array}{l}\text { - No formal mechanism, but individual } \\
\text { firms control subset of alliance activities }\end{array}$ \\
\hline SGA & Low & High & None & $\begin{array}{l}\text { - Sequential moves within period } \\
\text { - Firms consider alliance performance }\end{array}$ \\
\hline RAT & Medium & High & None & $\begin{array}{l}\text { - Sequential moves within period } \\
\text { - Firms consider alliance performance } \\
\text { - Ratification stage }\end{array}$ \\
\hline INT & High & High & High & - Single decision maker \\
\hline
\end{tabular}

\section{Level of exploration supplied by governance modes}

\begin{tabular}{|ccl|}
\hline & $\begin{array}{c}\text { Exploration } \\
\text { Level }\end{array}$ & \multicolumn{1}{c|}{$\begin{array}{c}\text { Exploration } \\
\text { Influences }\end{array}$} \\
\hline MOD & Very High & - Parochial decision making by firm managers \\
\hline SGA & High & - Parochial policy evaluations and implementation by alliance \\
\hline RAT & Medium & - Parochial policy evaluations by alliance \\
\hline INT & Low & - Ratification step \\
\hline
\end{tabular}

MOD, SGA, RAT and INT refer to the modular, self-governing alliance, ratified alliance, and integrated governance modes, respectively. 
Table 2

Performance, exploration and coordination, interdependence pattern 1

\begin{tabular}{|c|c|c|c|c|c|c|c|}
\hline \multirow{3}{*}{$\begin{array}{l}\text { Capability } \\
\text { Level }\end{array}$} & \multirow{3}{*}{$\begin{array}{l}\text { Gov. } \\
\text { Mode }\end{array}$} & & & \multicolumn{3}{|c|}{ Degree of Exploration } & \multirow{3}{*}{$\begin{array}{l}\text { Coordination } \\
\text { Failures }\end{array}$} \\
\hline & & \multicolumn{2}{|c|}{ Performance } & \multicolumn{2}{|c|}{$\begin{array}{l}\text { Percent of Choices } \\
\text { Evaluated }^{*}\end{array}$} & \multirow{2}{*}{$\begin{array}{l}\text { Sticking } \\
\text { Points }\end{array}$} & \\
\hline & & p. 10 & p. 200 & p. 10 & p.200 & & \\
\hline \multirow{4}{*}{ A } & MOD & 0.898 & 0.931 & 34.7 & 45.2 & 18.0 & 0 \\
\hline & $\mathrm{SG} \Lambda$ & 0.916 & 0.930 & 40.1 & 45.2 & 20.3 & 0 \\
\hline & $\mathrm{R} \wedge \mathrm{T}$ & 0.917 & 0.931 & 40.0 & 45.2 & 19.0 & 0 \\
\hline & INT & 0.849 & 0.931 & 25.3 & 45.2 & 18.5 & 0 \\
\hline \multirow{4}{*}{ B } & MOD & 0.951 & 0.951 & 55.3 & 55.3 & 17.9 & 0 \\
\hline & $\operatorname{SG} \Lambda$ & 0.951 & 0.951 & 55.3 & 55.3 & 19.8 & 0 \\
\hline & $\mathrm{R} \wedge \mathrm{T}$ & 0.951 & 0.951 & 55.3 & 55.3 & 18.5 & 0 \\
\hline & INT & 0.951 & 0.951 & 55.3 & 55.3 & 18.5 & 0 \\
\hline \multirow{4}{*}{ C } & MOD & 0.910 & 0.987 & 47.0 & 82.6 & 2.1 & 0 \\
\hline & $\operatorname{SG} \Lambda$ & 0.944 & 0.986 & 53.6 & 81.4 & 2.5 & 0 \\
\hline & $\mathrm{R} \wedge \mathrm{T}$ & 0.944 & 0.986 & 53.6 & 81.4 & 2.3 & 0 \\
\hline & INT & 0.855 & 0.983 & 34.3 & 80.3 & 2.2 & 0 \\
\hline \multirow{4}{*}{ D } & MOD & 0.991 & 0.991 & 90.3 & 90.3 & 2.2 & 0 \\
\hline & $\operatorname{SG} \Lambda$ & 0.993 & 0.993 & 89.6 & 89.6 & 2.3 & 0 \\
\hline & $\mathrm{R} \wedge \mathrm{T}$ & 0.993 & 0.993 & 89.6 & 89.6 & 2.0 & 0 \\
\hline & INT & 0.990 & 0.990 & 90.7 & 90.7 & 2.2 & 0 \\
\hline
\end{tabular}

MOD, SGA, RAT and INT refer to the modular, sclf-governing alliance, ratified alliance, and integrated forms, respectively. Performance refers to the sum of Firm 1 and Firm 2 performance at periods 10 and 200. Exploration is measured using two different metrics: (1) percent of choices evaluated: the running total of all contribution values accessed by the two firms at periods 10 and 200 as a result of the firms' decision making processes divided by the total number of such values on the landscape; and (2) sticking points: the average number of points on the landscape from which the two-firm system will not move. Coordination failures are measured as the number of periods between the beginning of the simulation and period 200 that total profit (Firm 1 and Firm 2) declines from one period to the next. All measures (except sticking points) are cvaluated and averaged across 10,000 simulations. Sticking points are averaged over 100 simulation runs.

* Pattern 1 has a total of 144 possible contribution values that can be evaluated. 
Table 3

Performance, exploration and coordination, interdependence pattern 4

\begin{tabular}{|c|c|c|c|c|c|c|c|}
\hline \multirow{3}{*}{$\begin{array}{l}\text { Capability } \\
\text { Level }\end{array}$} & \multirow{3}{*}{$\begin{array}{l}\text { Gov. } \\
\text { Mode }\end{array}$} & & & \multicolumn{3}{|c|}{ Degree of Exploration } & \multirow{3}{*}{$\begin{array}{l}\text { Coordination } \\
\text { Failures }\end{array}$} \\
\hline & & \multicolumn{2}{|c|}{ Performance } & \multicolumn{2}{|c|}{$\begin{array}{l}\text { Percent of Choices } \\
\text { Evaluated }^{*}\end{array}$} & \multirow{2}{*}{$\begin{array}{l}\text { Sticking } \\
\text { Points }\end{array}$} & \\
\hline & & p. 10 & p. 200 & p. 10 & p. 200 & & \\
\hline \multirow{4}{*}{ A } & MOD & 0.747 & 0.842 & 0.3 & 1.2 & 83.8 & 10.3 \\
\hline & SG $\Lambda$ & 0.768 & 0.833 & 0.4 & 1.0 & 97.5 & 6.0 \\
\hline & $\mathrm{R} \wedge \mathrm{T}$ & 0.784 & 0.829 & 0.3 & 0.7 & 193.1 & 3.1 \\
\hline & INT & 0.788 & 0.829 & 0.2 & 0.5 & 315.1 & 0 \\
\hline \multirow{4}{*}{ B } & MOD & 0.731 & 0.761 & 1.2 & 1.7 & 83.8 & 47.0 \\
\hline & $\mathrm{SG} \Lambda$ & 0.790 & 0.807 & 1.0 & 1.1 & 97.5 & 21.9 \\
\hline & $R \wedge T$ & 0.776 & 0.781 & 0.9 & 0.9 & 193.1 & 30.5 \\
\hline & INT & 0.845 & 0.845 & 0.7 & 0.7 & 315.1 & 0 \\
\hline \multirow{4}{*}{$\mathrm{C}$} & MOD & 0.740 & 0.818 & 0.3 & 4.3 & 8.5 & 35.7 \\
\hline & $\mathrm{SG} \Lambda$ & 0.760 & 0.865 & 0.5 & 3.6 & 20.4 & 21.6 \\
\hline & $\mathrm{R} \wedge \mathrm{T}$ & 0.781 & 0.873 & 0.5 & 2.2 & 50.1 & 9.6 \\
\hline & INT & 0.800 & 0.895 & 0.3 & 2.5 & 51.9 & 0 \\
\hline \multirow{4}{*}{ D } & MOD & 0.690 & 0.747 & 4.6 & 12.3 & 8.5 & 71.6 \\
\hline & $\mathrm{SG} \Lambda$ & 0.780 & 0.831 & 3.0 & 4.6 & 20.4 & 32.4 \\
\hline & $\mathrm{R} \wedge \mathrm{T}$ & 0.781 & 0.795 & 2.6 & 3.0 & 50.1 & 42.9 \\
\hline & INT & 0.912 & 0.912 & 4.0 & 4.0 & 51.9 & 0 \\
\hline
\end{tabular}

MOD, SGA, RAT and INT refer to the modular, self-governing alliance, ratificd alliance, and integrated forms, respectively. Performance refers to the sum of Firm 1 and Firm 2 performance at periods 10 and 200. Exploration is measured using two different metrics: (1) percent of choices evaluated: the running total of all contribution values accessed by the two firms at periods 10 and 200 as a result of the firms' decision making processes divided by the total number of such values on the landscape; and (2) sticking points: the average number of points on the landscape from which the two-firm system will not move. Coordination failures are measured as the number of periods between the beginning of the simulation and period 200 that total profit (Firm 1 and Firm 2) declines from one period to the next. All measures (except sticking points) are evaluated and averaged across 10,000 simulations. Sticking points are averaged over 100 simulation runs.

*Pattern 4 has a total of 49,152 possible contribution values that can be evaluated. 
Table 4

Relative effects of coordination and exploration

\begin{tabular}{|c|c|c|c|c|}
\hline $\begin{array}{l}\text { Dependent variable: } \\
\text { Performance }\end{array}$ & \multicolumn{2}{|c|}{$\begin{array}{c}\text { (4-1) } \\
\text { period } 10\end{array}$} & \multicolumn{2}{|c|}{$\begin{array}{c}\mathbf{( 4 - 2 )} \\
\text { period } 200\end{array}$} \\
\hline Coordination failure & -0.156 & {$[0.002$} & -0.161 & {$[0.001]$} \\
\hline Exploration & 0.189 & {$[0.001$} & 0.135 & {$[0.001]$} \\
\hline$P 2$ dummy & -0.012 & {$[0.001$} & -0.016 & {$[0.001]$} \\
\hline P3 dummy & -0.005 & {$[0.001]$} & -0.010 & {$[0.001]$} \\
\hline P4 dummy & -0.028 & {$[0.001]$} & -0.011 & {$[0.001]$} \\
\hline$P 3 *$ coord failure & -0.085 & {$[0.002$} & -0.105 & {$[0.002]$} \\
\hline P4 * coord failure & -0.191 & {$[0.002$} & -0.269 & {$[0.002]$} \\
\hline$P 2 *$ exploration & 0.013 & {$\left[0.001^{-}\right.$} & 0.013 & {$[0.001]$} \\
\hline$P 3 *$ exploration & 0.948 & {$[0.008$} & 0.528 & {$[0.005]$} \\
\hline$P 4 *$ exploration & 0.871 & {$[0.013$} & 0.276 & {$[0.004]$} \\
\hline Constant & 0.830 & {$\left[0.001^{\circ}\right.$} & 0.873 & {$[0.001]$} \\
\hline Model $\mathrm{R}^{2}$ & \multicolumn{2}{|c|}{0.518} & \multicolumn{2}{|c|}{0.574} \\
\hline
\end{tabular}

This table shows OLS regressions of firm performance (sum of Firm 1 and Firm 2) at period 10 or period 200. Exploration is measured by percent of choices evaluated and coordination failure is measurcd by coordination failure percent. All cocfficients are significant at the $\mathrm{p}<0.001 \mathrm{lcvcl}$. Each specification contains 640,000 observations: 4 patterns, 4 governance modes and 4 capability levels, across 10,000 simulations. 
Europe Campus

Boulevard de Constance,

77305 Fontainebleau Cedex, France

Tel: $+33(0) 160724000$

Fax: $+33(0) 16074$ 00/01

\section{Asia Campus}

1 Ayer Rajah Avenue, Singapore 138676

Tel: +65 67995388

Fax: +65 67995399

www.insead.edu

\section{INSEAD}

The Business School

for the World 